\title{
Copy Number Variants in Obesity-Related Syndromes: Review and Perspectives on Novel Molecular Approaches
}

\author{
Carla Sustek D'Angelo and Celia Priszkulnik Koiffmann \\ Human Genome and Stem Cell Center, Department of Genetics and Evolutionary Biology, Institute of Biosciences, \\ University of Sao Paulo, 277 Rua do Matao, Rooms 204 and 209, 05508-090 Sao Paulo, SP, Brazil \\ Correspondence should be addressed to Carla Sustek D’Angelo, cdangelo@ib.usp.br
}

Received 30 August 2012; Accepted 9 October 2012

Academic Editor: David Allison

Copyright ( 92012 C. S. D’Angelo and C. P. Koiffmann. This is an open access article distributed under the Creative Commons Attribution License, which permits unrestricted use, distribution, and reproduction in any medium, provided the original work is properly cited.

\begin{abstract}
In recent decades, obesity has reached epidemic proportions worldwide and became a major concern in public health. Despite heritability estimates of 40 to $70 \%$ and the long-recognized genetic basis of obesity in a number of rare cases, the list of common obesity susceptibility variants by the currently published genome-wide association studies (GWASs) only explain a small proportion of the individual variation in risk of obesity. It was not until very recently that GWASs of copy number variants (CNVs) in individuals with extreme phenotypes reported a number of large and rare CNVs conferring high risk to obesity, and specifically deletions on chromosome 16p11.2. In this paper, we comment on the recent advances in the field of genetics of obesity with an emphasis on the genes and genomic regions implicated in highly penetrant forms of obesity associated with developmental disorders. Array genomic hybridization in this patient population has afforded discovery opportunities for CNVs that have not previously been detectable. This information can be used to generate new diagnostic arrays and sequencing platforms, which will likely enhance detection of known genetic conditions with the potential to elucidate new disease genes and ultimately help in developing a next-generation sequencing protocol relevant to clinical practice.
\end{abstract}

\section{Introduction}

Obesity is a highly heritable complex disorder defined by the World Health Organization (WHO) as a body mass index $(\mathrm{BMI}) \geq 30 \mathrm{~kg} / \mathrm{m}^{2}$ [1]. It is also one of the greatest public health challenges of modern times, given its increasing prevalence to epidemic proportions worldwide. The major concern of the "obesity epidemic" is that obesity is a preventable risk factor for some of the leading causes of mortality, including heart disease, type II diabetes, and certain types of cancers $[2,3]$. This rapid global rise in obesity has been largely driven by lifestyle and environmental changes. Despite that, genetic variation plays a major role in determining the interindividual differences in susceptibility or resistance to the current "obesogenic" environment, which is characterized by easy access to high-calorie food and reduced energy expenditure [4]. Indeed, twin and adoption studies have revealed that heritability of obesity is about $40-70 \%[5,6]$; although it may be that current heritability estimates are inflated. Furthermore, there are a number of rare monogenic causes of obesity [7] and genetic syndromes that have obesity as a central feature [8-10], which in fact provided the first indications of how obesity development might be strongly influenced by genes.

Given the estimated heritability of BMI, extensive efforts have been made for the past several years to identify the genetic factors underlying the heritable risk of obesity. While there has been much concentration on genetics research focusing on common obesity susceptibility variants, the so far established loci confer only a small fraction of the inter-individual BMI variation, and there is still much to be learned regarding the biological implications of the associations. This is in sharp contrast to the successful gene identification in rare forms of obesity. In this paper, we review the recent advances in the field of genetics of obesity with an emphasis on genes and genomic regions implicated in highly penetrant forms of human obesity presenting as part of phenotypically well-defined syndromes, 
or more generally, in the presence of developmental delay (DD), intellectual disabilities (ID), and/or malformative features. The outcome of array genomic hybridization in this patient population will likely enhance our understanding of obesogenic pathways-findings that may lead to new targets for drug design and to therapeutic options for each syndrome and obesity in general —and also help in developing novel methodological approaches to the study of obesity.

\section{Common Obesity Research}

One common theory to explain how genes contribute to obesity in the current environment is the accumulation of "energy-thrifty genes"-genes which enable individuals to efficiently collect and process food to deposit fat during periods of food abundance-that have held significant survival advantages in the past when food sources were rather scarce ("thrifty-genotype" hypothesis [11]). This hypothesis implies that individuals who carry the "thrifty" genes that helped our ancestors to survive famines are more susceptible to obesity in modern societies with a constant abundance of food and also explains the variation in how people respond to the same unhealthy environmental pressures. Yet, despite a relatively high heritability, the search for obesity susceptibility genes has been a challenging task.

Early studies aiming to identify the gene variants underlying susceptibility to common obesity suffered from several limitations inherent to the methodologies available at the time (i.e., candidate genes and family-based linkage studies) and had limited success [12]. Progress in the field has been swift with the advent of recent hypothesis-free genomewide association studies (GWASs) using high-density singlenucleotide polymorphism (SNP) genotyping arrays, or "SNP arrays", preceded by sequencing of the human genome and the creation of databases of SNPs (such as dbSNPs and the International HapMap). GWASs typically focus on SNP markers that capture linkage disequilibrium (LD) relationships across the whole genome ("tag" SNPs) and differ in frequency between cases and controls, or between individuals with different phenotypic values, in samples of sufficient size to reach genome-wide level of statistical significance (e.g., $P<10^{-8}$ ) $[13,14]$. GWAS is currently the most commonly used method to identify genetic loci associated with a particular phenotype, but has also already been completed, in a short period of time, for most common human diseases and related traits, mainly in European ancestry populations [15].

As for BMI, there have been to date four large GWAS meta-analyses in general populations of European descent, each with increasing sample sizes (with $n$ ranging from 16876 to 123865 individuals) to detect variants with smaller effect sizes or lower allele frequencies not detected by the preceding ones [16]. The fourth large-scale GWAS meta-analysis performed by the genetic investigation of anthropometric traits (GIANT) consortium has discovered a total of 32 loci robustly $\left(P<5<10^{-8}\right.$; odds ratio $=1.016$ - to 1.203 fold) associated with BMI [17]. The three most significantly associated SNPs for BMI included rs1558902 within intron
1 of the fat mass and obesity-associated (FTO) gene $(P=$ $4.8 \times 10^{-120}$; odds ratio $\left.=1.203\right)$, rs2867125 near TMEM18 $\left(P=2.77 \times 10^{-49}\right.$; odds ratio $\left.=1.134\right)$, and rs571312 near MC4R $\left(P=6.43 \times 10^{-42} ;\right.$ odds ratio $\left.=1.108\right)$. Notably, some associations are common even with obesity-related traits and consistent across multiple ethnic groups, most commonly in the FTO and near-MC4R loci [16]. However, the effect sizes detected are smaller than anticipated: the combined risk alleles explain only a fraction $(\sim 1.45 \%)$ of the interindividual variation in BMI, with the FTO locus accounting for the largest proportion in variation $(0.34 \%)$; for each additional risk allele in $F T O$, BMI increases by $0.39 \mathrm{~kg} / \mathrm{m}^{2}$ $(\sim 1.1 \mathrm{~kg}$ for someone $170 \mathrm{~cm}$ tall $)[16,17]$. It thus follows that the risk alleles discovered in the most recent and largest GWAS for BMI are not sufficient to have any clinical value and additional genes or different types of genetic variants remain to be discovered.

Despite the very limited predictive value and the fact that the causal variants and/or molecular basis of risk etiology remain largely unclear (very few common variants for disease have been functionally validated), GWASs have provided valuable insights into the genetics of obesity, particularly about its biology. Several of the likely causal genes in predisposition to obesity are highly expressed or known to act in the central nervous system (CNS) and thus are thought to be involved in obesity susceptibility via CNSmediated effects [18]. FTO, for instance, is one of the best investigated obesity-associated genes of the GWAS era. The FTO mRNA is most highly expressed in the brain and especially in the hypothalamus [19], an area known from rare monogenic forms of obesity to be critical in the control of energy homeostasis. There is additional evidence that FTO expression in the arcuate nucleus (ARC) of the hypothalamus is bidirectionally regulated as a function of nutritional status (i.e., feeding and fasting), and that changes in FTO expression levels in the ARC can bidirectionally influence food intake [20]. Despite these direct evidences that FTO is functionally involved in energy homeostasis by central regulation of food intake, the mechanisms by which FTO increases risk of obesity are still not fully understood but may relate to epigenetic processes through FTO gain of expression $[19,20]$.

A recent work has shown expression of fourteen likely causal obesity risk genes (FTO, MC4R, BDNF, TMEM18, KCTD15, NEGR1, NRXN3, ETV5, MTCH2, SEC16B, TFAP2B, GNPDA2, FAIM2, and LYPLAL1) in the hypothalamus of both obese and lean rats, which either support or bring new evidence for a potential central effect of these genes on energy homeostasis [21]. Another observation reinforcing the role of genes involved in the central regulation of food intake in obesity predisposition is that so far, three obesity susceptibility loci are located near genes (MC4R, SH2B1, and BDNF) that have already been shown to carry deleterious mutations disrupting hypothalamic functions and leading to monogenic forms of early-onset obesity with hyperphagia as a common feature. Moreover, "synthetic associations" [22], while theoretically possible, are unlikely to be responsible for many of the GWAS signals that have been reported [23], and there is no evidence supporting 
this hypothesis at the MC4R locus [24]. Following this, one can expect that the GWAS-derived loci should be useful in clinical practice, if they point towards highly relevant candidate genes that may harbor rare mutations with large effects.

One important consideration to address the issue of "missing heritability," that is observed not only in obesity but for most of the conditions for which GWASs have so far been carried out, is that GWAS and SNPs selection in commercial genotyping arrays have been largely driven by the common disease-common variant (CDCV) hypothesis, which states that the heritability of common diseases is more strongly influenced by the additive effects of a few common allelic variants, which are present in more than $1-5 \%$ of the population $[25,26]$. Therefore, the SNPs that are on the SNP chips have been selected to be common (most have a minor allele frequency (MAF) of 5\%), and the proportion of heritability that can be captured with common SNPs depends on how well causal variants are tagged by these SNPs. As with BMI, the proportion of heritability explained by genome-wide significant SNPs is less than $2 \%$, but this percentage rises to almost $20 \%$ if the analysis is extended to common SNPs that do not reach genome-wide significance [27]. This proportion of variance that lacks statistical significance (false negatives) is possible due to ungenotyped causal variants that have a lower allele frequency than SNPs in the GWAS (i.e., less common or rare variants), and that are in low LD with genotyped SNPs. These findings further give support to the growing interest in the role of low frequency $(0.5<\mathrm{MAF}<5 \%)$ or rare $(\mathrm{MAF}<0.5 \%)$ sequence variants and other forms of genetic variation, in particular genomic structural variants. Indeed, genome copy number variants (CNVs) - a form of structural variation-instead of SNPs are now recognized as the prevalent form of genetic variation with potential clinical relevance in a number of diseases [28-30], and the involvement of CNVs in complex diseases is an area under intense investigation.

\subsection{Genome-Wide Association of Copy Number Variants.} CNVs are traditionally defined as DNA segments greater than $1 \mathrm{~kb}$ in length that are present at a variable copy number (gains and losses of DNA) across individuals [31]. The first evidence that copy-number alterations can influence human phenotypes came from sporadic diseases (resulting from de novo CNVs), termed "genomic disorders," which are defined as diseases caused by genomic rearrangements affecting dosage-sensitive genes $[32,33]$. CNVs may affect the expression of genes in several different ways. The most common mechanisms whereby a CNV may convey a phenotype are gene dosage, gene disruption, and position effects [31]. Given these observations, CNVs have been predicted to account for a significant component of variation in complex diseases risk. Indeed, emerging data suggest that this mechanism of mutation contributes to both common and rare diseases [34]. However, despite the fact that most of the differences between any two individuals $(\sim 80 \%)$ arise from a limited set of common copy number polymorphisms (CNPs) (CNVs at
$>5 \%$ frequency) [35], the release of a reference map of human CNVs in the HapMap populations [34] followed by a comprehensive genome-wide association study of common copy-number variation in eight common human diseases ( $\sim 19000$ individuals) indicated that common CNVs are not likely to contribute to disease susceptibility beyond common SNPs in LD [36]. This is because, in fact, common CNVs are well captured by SNPs typed in GWAS as a result of strong LD, implying that their role in common diseases has already been explored indirectly via SNP-based GWAS [36]. Nevertheless, the importance of CNVs resides in the fact that, due to their potential functional impact, CNVs in strong LD with the trait-associated SNPs are expected-and some have already been shown-to be the functional variants for the association signals of GWAS [34, 36]. Notably, $\sim 88 \%$ of currently identified disease- and trait-associated SNPs are either intronic or intergenic, and most of these variants did not appear to be functional [37]. However, recent ENCODE (ENCyclopedia Of DNA Elements) data demonstrate that an appreciable proportion of GWAS SNPs might represent the actual functional variants [38].

In obesity, using a SNP tagging approach, two of the 32 confirmed BMI SNPs were found to tag common CNVs: rs2815752 tagging a $45 \mathrm{~kb}$ deletion near the neuronal growth regulator (NEGR1) gene [17] and rs12444979 tagging a $21 \mathrm{~kb}$ deletion that lies $50 \mathrm{~kb}$ upstream of GPRC5B [39]. In addition, copy number analysis of GWAS data in two discovery samples ascertained for early-onset (extreme) obesity confirmed the CNV near NEGR1 and led to the identification of a CNV at 10q11.22 encompassing one important obesity gene (PPYR1) that was initially described in an adult Chinese population-based sample [40], as well as of another new CNV at $11 \mathrm{q} 11$ spanning $\sim 80 \mathrm{~kb}$ and covering exclusively three olfactory receptor genes (OR4O, OR4S2, and OR4C6) [41].

Large and rare CNVs ( $>500 \mathrm{~kb},<1 \%$ ) - as opposed to the vast majority of inherited CNPs which are much smallerhave been shown to contribute significantly to the risk of common complex disorders, such as that $5 \%$ of cases of schizophrenia and of autism have each been attributed to CNVs at fewer than half a dozen genomic locations, whose effects are less highly penetrant than Mendelian mutations [42]. Several rare, obesity-specific CNVs have been detected by genome-wide studies of individuals with extreme phenotypes. In one such study, Bochukova et al. [43] examined 300 Caucasians patients with early-onset obesity (half of them also showing developmental disorders) and observed a twofold enrichment of large and rare deletions in patients compared to 7366 healthy controls examined $(P<0.001)$. They also found an enrichment of a number of recurrent (present in two or more individuals) CNVs in patients relative to controls. Among these, they identified a $220 \mathrm{~kb}$ deletion on chromosome $16 \mathrm{p} 11.2$ (28.7-28.9 Mb, hg18; NCBI build 36) containing the $S H 2 B 1$ gene in three patients who had inherited the deletion from obese parents. Additionally, two more cases were identified in a replication cohort of 1062 Caucasian patients with severe obesity alone, and the deletion cosegregated with obesity in one of these families with available samples. The reported overall 
prevalence of the SH2B1-containing deletion in patients with severe early-onset obesity alone was $0.41 \%$ (5 out of 1219 ; $0.41 \%)$ compared to only 2 out of $7366(0.027 \%)$ controls $(P<0.001)$.

In a parallel study, Walters et al. [44] identified a separate, proximal deletion of approximately $600 \mathrm{~kb}$ at chromosome $16 \mathrm{p} 11.2$ (29.5-30.1 Mb, hg18; NCBI build 36) containing the TBX6 gene in $2.9 \%$ (9 out of 312) of obese children whose ascertainment also included cognitive deficits/malformations. The deletion was also present in $0.4 \%$ of individuals (15 out of 4197 ) ascertained only for obesity but not in normal weight controls and in $0.6 \%$ of patients (22 out of 3947) with DD and/or malformations but without selection for obesity. Pooling the data obtained from a general population cohort (11856 subjects in total) with those from the obesity cohorts in an overall case-control association analysis, the authors found at or near genomewide significant evidence for association of the $16 \mathrm{p} 11.2$ deletions with obesity $\left(P=5.8 \times 10^{-7}\right.$; odds ratio $=$ $29.8)$ and morbid obesity $\left(P=6.4 \times 10^{-8}\right.$; odds ratio $=$ 43.0). Another study by Wang et al. [45] also found strong support for large and rare CNVs, especially gene-disrupting deletions, contributing with higher risk to obesity than common variants. In that study, CNVs $>1.0 \mathrm{Mb}$ were found overrepresented among 430 case subjects of European ancestry who had moderate to extreme obesity versus 379 controls subjects who had never been obese (odds ratio = 1.5), while CNVs $>2.0 \mathrm{Mb}$ were present in $1.2 \%$ of obese case subjects ( 5 out of 427 ) but absent in the lean controls (odd). A total of eleven CNVs representing major risk factors for obesity were uncovered by this study, several of which disrupting potential candidate genes (e.g., UCP1, IL15). Finally, a subsequent larger study uncovered 17 additional rare CNVs that were unique to at least three extremely obese children among 1080 European American (EA) cases and in none of the 2500 lean controls, of which eight (47.1\%) also replicated exclusively in an independent case-control data set from African Ancestry [46].

It is important to mention that there are several concerns regarding GWAS-based CNV analysis, specifically with regard, the inaccuracy of CNV calling algorithms in detecting particularly small CNVs, common CNVs, and duplications using SNP arrays, and the impact of CNV genotyping call errors on association analyses has not been extensively studied $[47,48]$.

\section{The Chromosome 16p11.2 Locus}

The short arm of human chromosome 16 is particularly enriched for large segmental duplications (SDs)—duplicated sequences of $>1 \mathrm{~kb}$ with $90 \%$ or more sequence identity in the reference human genome assembly-that serve as substrates for unequal crossover or nonallelic homologous recombination (NAHR), resulting in recurrent duplications and deletions and predisposing this region to diseases [49]. Several distinct, recurring imbalances of $16 \mathrm{p}$ have been associated with abnormal phenotypes by genotyping of large case-control studies, which together with other recurrent genomic imbalances (e.g., 1q21.1 and 16p12.1 deletions) escape syndromic classification, representing instead a subset of genomic disorders that shows association with variable phenotypes (e.g., DD/ID, congenital malformations, epilepsy, schizophrenia, autism, cardiac and renal anomalies, and obesity) $[49,50]$. These CNV loci are also associated with highly variable expressivity (or reduced penetrance) in that they are also found at lower frequencies in the control populations as well as in family members who are often unaffected (or presenting with milder phenotypes). Although the cause of phenotypic variability remains largely unexplained, recent studies show that the presence of "two-hit" CNVs ("two-hit" model) with additive or epistatic effects can contribute to variability associated with these CNVs [49-51].

Recently, two large copy number variant case-control studies have demonstrated and confirmed the pathogenicity of the aforementioned obesity-associated 16p11.2 deletions. Exploiting a large CNV dataset derived from a consortium of clinical laboratories (the International Standards for Cytogenomic Arrays consortium, ISCA; https://www.iscaconsortium.org/) involving 15749 cases and 10118 controls, Kaminsky et al. [52] observed the proximal 16 p11.2 deletion $($ TBX6) in 67 cases of intellectual and developmental disabilities compared to only five occurrences among the control population $\left(P=6.34^{-10}\right.$, odds ratio $=$ $8.64)$. In terms of frequency, the $16 \mathrm{p} 11.2$ deletion was second only (and nearly as often as) to the velocardiofacial/DiGeorge syndrome (VCF/DGS) deletion. Cooper et al. [53] compared CNVs in 15767 children with a general diagnosis of DD/ID to CNVs in 8329 unaffected adult controls and found 64 instances of $16 \mathrm{p} 11.2$ proximal (TBX6) deletions among cases compared to 3 controls $\left(P=3.4 \times 10^{-9}\right.$; penetrance $\left.=0.96\right)$ and 15 instances of $16 \mathrm{p} 11.2$ distal $(\mathrm{SH} 2 \mathrm{~B} 1)$ deletions among cases versus one control $(P=0.0107$; penetrance $=0.94)$. A previous case-control study in a clinical setting found this recurrent $\mathrm{SH} 2 \mathrm{B1}$-containing microdeletion in $0.13 \%$ (31 out of 23084) of patients with a variety of different clinical findings compared with a single case of deletion among 7700 phenotypically normal controls $(0.013 \% ; P=0.003)$ [54]. Notably, the authors not only observed a high frequency of obesity in individuals with this deletion but also DD/ID, aside from other variable phenotypic features, highlighting the pathogenicity of the recurrent $220 \mathrm{~kb} 16 \mathrm{p} 11.2$ deletion and its link to both obesity and DD/ID.

Originally, deletions of the more proximal $600 \mathrm{~kb}$ region of $16 \mathrm{p} 11.2$ were reported as a recurrent microdeletion in individuals with autism spectrum disorder (ASD); this explains why it is usually referred to as the autism-associated proximal 16p11.2 deletion. However, as more case-control studies were undertaken, it became clear that this deletion contributes to the etiology of both DD/ID and ASD [55]. It was only after that the same event was documented to increase the risk of obesity [44]. Interestingly, the reciprocal 16 p11.2 duplication was recently shown to confer an increased risk for being clinically underweight (BMI $\leq$ 18.5), with similar effects among medically ascertained (ID/DD and psychiatric cohorts) and nonmedically ascertained (population-based cohorts) carriers [56]. In fact, 
the duplication conferred an 8.3-fold increased risk in adulthood of being underweight $\left(P=1.53 \times 10^{-10}\right)$. Furthermore, gene expression levels of the 27 genes mapping to 16 p 11.2 were shown to correlate positively with gene dosage in deletion and duplication carriers. Thus, deletion and duplication in 16p11.2 demonstrates that reciprocal changes in gene dosage (i.e., haploinsufficiency and triplosensitivity) at this locus have opposite effects on BMI.

A major challenge for such CNV "hotspots" flanked by duplications has been the paucity of patients described with smaller or atypical rearrangements, which would allow reducing the disease-associated critical region. Accordingly, the breakpoints of the distal and proximal 16p11.2 deletions have been reported as identical in most individuals, and thus hampering delineation of the dosage-sensitive gene(s) that underlie the observed phentoypes. However, there is mounting evidence supporting a role for haploinsufficiency of SH2B1 in the obesity phenotype of patients with the $220 \mathrm{~kb}$ deletion: it encodes an adaptor protein involved in the leptin and insulin signaling; it is a likely causal obesity gene from the GWAS era; mice lacking Sh2B1 are characterized by obesity and severe insulin resistance $[17,57]$. On the contrary, there are no data at present pointing towards particular candidate genes for obesity within the more proximal $600 \mathrm{~kb}$ region of $16 \mathrm{p} 11.2$, and several might be of potential functional relevance (e.g., BOLA2/B, SULT1A4/3, SPN, MAZ, MVP, KCTD13, TAOK2, PPP4C, GDPD3, and MAPK3) [56]. The T-box 6 (TBX6) gene, a transcription factor involved in regulation of early developmental processes, has been proposed to play a role in the congenital anomalies among a series of patients [58].

\section{Monogenic Forms of Obesity}

Monogenic forms of obesity refer to a highly penetrant form of the disease resulting from mutations in, or deletions of, single genes (Mendelian conditions) [7]. To date, there are eight well-established monogenic obesity genes: leptin $(L E P)$, leptin receptor $(L E P R)$, proopiomelanocortin $(P O M C)$, prohormone convertase 1 (PCSK1), melanocortin 4 receptor $(M C 4 R)$, single-minded homologue 1 (SIM1), brain-derived neurotrophic factor $(B D N F)$, and neurotrophic tyrosine kinase receptor type 2 (NTRK2). Mutations in these eight genes are known to cause earlyonset obesity and hyperphagia and may account for up to $10 \%$ of severely obese children [59]. Originally identified by study of consanguineous families, fully penetrant recessive forms of early-onset severe obesity are associated with complete inactivation of five such genes (LEP, LEPR, POMC, $P C S K 1$, and MC4R) involved in the leptin-melanocortin signaling pathway [18]. These recessive forms of obesity confirmed the central role of this pathway in the longterm regulation of energy balance. In short, the adipocyte hormone leptin acts via its receptors to inhibit food intake through reciprocal regulation of POMC and AgRP/NPY (agouti-related protein/neuropeptide $\mathrm{Y}$ ) neurons in the arcuate nucleus of the hypothalamus (ARC) and consequent activation of MC4R in the paraventricular nucleus (PVH) following the binding of $\alpha$-melanocyte stimulating hormone $(\alpha-\mathrm{MSH})$, a cleavage product of the POMC transcript by PCSK1-, which in turn provides an anorexigenic/satiety signal through the activation of downstream effectors [7, $12,13]$. The leptin-melanocortin signaling pathway as a molecular therapeutic target for treating obesity leads to the first and until now only effective pharmacotherapy for obesity, that is, recombinant human leptin replacement in the rare cases of congenital leptin deficiency [7].

These recessive and most severe forms of human obesity are accompanied by normal development and typically include additional and more specific features, such as adrenal insufficiency and red hair $(P O M C)$, reactive hypoglycemia and intestinal dysfunction (PCSK1), hyperinsulinaemia and accelerated height $(M C 4 R)$, extremely low serum leptin levels $(L E P)$, and hypogonadotropic hypogonadism and impaired immune function (LEP, LEPR) [59]. On the other hand, heterozygosity for deleterious coding mutations in $M C 4 R$, $L E P, L E P R$, and POMC has been associated with a less severe, nonfully penetrant form of obesity [19], implicating these genes in susceptibility to obesity at the population level as well. In fact, mutations in $M C 4 R$ are the most common recognized cause of monogenic obesity, with the vast majority of cases described so far having heterozygous, dominantly inherited mutations. MC4R mutations have a population prevalence of at least 1 in $2000(0.05 \%)$, are found in $0.5 \%$ to $1 \%$ of obese adults, and are accountable for $6 \%$ of all severe cases of the disease starting in childhood [60].

Additionally, partial deficiency for SIM1, BDNF, and NTRK2 genes, involved in the functioning of the hypothalamus and specifically downstream of MC4R-expressing neurons [14], lead to severe hyperphagic obesity, accompanied by $\mathrm{DD}$ and syndromic features in humans [19]. A single case of haploinsufficiency of SIM1 caused by a de novo balanced translocation between chromosomes $1 \mathrm{p} 22.1$ and 6q16.2, which disrupts SIM1, was reported in a girl who had earlyonset severe obesity with no other developmental abnormalities or syndromic features described [61]. Patients who are obese because of interstitial deletions of chromosome $6 \mathrm{q}$ that involve the SIM1 locus have been reported with neurodevelopmental issues and specific phenotypes resembling those of Prader-Willi syndrome (PWS) [62], the most common syndromic form of obesity. A single case of functional deficiency of BDNF, caused by a de novo chromosomal inversion that included the BDNF locus, was reported in an 8 -year-old girl who presented with hyperphagia, obesity, and additionally impaired cognition [63]. Furthermore, BDNF haploinsufficiency was implicated directly in the obesity phenotype of a subset of individuals suffering from Wilms tumor-aniridia-genitourinary anomalies-mental retardation (WAGR) syndrome who, in addition to the obligatory heterozygous deletion of the PAX6 and WT1 genes, were demonstrated to have longer deletions including the BDNF locus at 11 p14.1 [64]. Finally, a de novo missense mutation in the receptor for BDNF, NTRK2, was found in an 8-yearold male with a complex developmental syndrome and severe obesity [65]. 


\section{Syndromic Forms of Obesity}

Obesity syndromes, sometimes referred to as obesity-related syndromes, are also associated with DD/ID, dysmorphic features, and/or congenital anomalies. The latest Human Obesity Gene Map update reported 50 loci related to Mendelian syndromes relevant to human obesity [66]. Syndromic forms of obesity typically arise from chromosomal abnormalities at several genomic regions (both autosomal and $\mathrm{X}$-linked), whilst a few single-gene mutations resulting in pleiotropic syndromes with obesity as a central feature are included in the same category. One of the most wellknown forms of syndromic obesity (also the first to be described in the literature) is PWS, which manifests as infantile hypotonia, genital hypoplasia, and neonatal feeding difficulties, followed by hyperphagia leading to profound obesity in early childhood and into adulthood [67]. Other typical examples are Albright hereditary osteodystrophy (AHO), Bardet-Biedl (BBS), Alström (ALS), Carpenter (or acrocephalopolysyndactyly type II), Cohen (CS), BörjesonForssman-Lehmann (BFLS), and MEHMO (mental retardation, epileptic seizures, hypogenitalism, microcephaly, and obesity) syndromes [8-10]. PWS and AHO are also examples of imprinting disorders featuring obesity as one of their clinical characteristics [14]. PWS is due to the lack of expression of imprinted genes on chromosome 15q11q13 that are usually only expressed on the paternally inherited chromosome [67]. AHO is an autosomal dominant disorder characterized by short stature, obesity, skeletal defects, and impaired olfaction, which is caused by germ line mutations that disrupt imprinting in the maternal allele of the GNAS1 gene [68].

Significant advances in the identification and characterization of the genes implicated in these syndromes have been made in the last few years, revealing interesting genetic pathways involved in syndrome pathology which may be leading to obesity. For example, in PWS there is strong evidence in support of a critical role for the C/D box containing small nucleolar RNA (snoRNA) genes, especially of the snoRNA SNORD116 cluster (HBII-85), in the major components of the disease phenotype, such as infantile hypotonia, earlyonset morbid obesity, and hypogonadism. This comes from recent data from three published patients manifesting the major features of PWS, but with normal DNA methylation analysis, who were discovered by array comparative genomic hybridization (array CGH) investigation with $\sim 174-236 \mathrm{~kb}$ overlapping microdeletions at $15 \mathrm{q} 11.2$, which reduced the critical region for PWS to the C/D box snoRNA SNORD116 cluster [69-71]. There exist a number of paternally expressed genes (e.g., MKRN3, MAGEL2, NDN, SNURF-SNRPN, and multiple snoRNAs) within the imprinted $15 \mathrm{q} 11 \mathrm{q} 13$ region. However, paternal deficiency of MKRN3, MAGEL2, and $N D N$ is not sufficient to cause PWS [72], and the SNRPN, initially considered a primary PWS candidate gene, was ruled out as having a major role in PWS from analysis of PWS cases with balanced translocations [67]. PWS is likely caused by a hypothalamic dysfunction, but further investigation is still needed to determine how these noncoding RNAs, predicted to regulate the level, splicing, or modification of other RNAs, could lead to hyperphagia and obesity. Importantly, although no known pharmacologic agent that can diminish hyperphagia is effective, earlyonset intervention, such as dietary restrictions and behavior modification, has been proven to be successful in preventing the inappropriate weight gain [67]. Additionally, growth hormone $(\mathrm{GH})$ therapy has resulted in dramatic benefits to the phenotype, including decrease in body fat mass, increase in lean body mass, and linear growth velocity [67]. Interestingly, a recent study reported three CNVs (with occurrence rates higher than 1\%) at the PWS $15 \mathrm{q} 11.2$ region that were significantly associated with body fat mass $(P<$ 0.05 ) in the general white populations, with a higher copy number $(\mathrm{CN})$ resulting in an increase of $5.08-9.77 \mathrm{~kg}$ in body fat mass [73]. Thus, CNVs at the PWS critical region may contribute to common obesity.

In BBS, ALS, and Carpenter syndromes, all of each of autosomal recessive inheritance, the disease phenotype has been linked to abnormal formation or function of the primary cilia [8-10], which are microtubule-based subcellular organelles projecting from the surface of nearly all human cell types that mainly serve as a sensory organelle for the cell. The integrity of primary cilium and maintenance of ciliary function through their coordination with intraflagellar transport (IFT), a specialized trafficking system in primary cilia, are both required to properly activate primary cilia-mediated cellular signaling, and defects in genes encoding components of the cilium have been linked to a constellation of phenotypically and genetically overlapping human diseases, which are collectively known as ciliopathies [74]. BBS (obesity, retinitis pigmentosa, renal anomalies, postaxial polydactyly, learning disabilities, and defects in the urogenital tract) is the prototypical human genetic disorder associated with ciliary dysfunction and obesity. Fifteen BBS genes (BBS1-15) have been identified accounting for about $80 \%$ of the known cases of BBS [75]. Among the known BBS proteins, seven proteins (BBS1, BBS2, BBS4, BBS5, BBS7, and BBS9) collectively form part of the IFT complex of the primary cilium, known as the BBSome. Other known BBS proteins appear to be crucial for the recruitment of this complex onto the ciliary membrane (BBS3) or in mediating the assembly of the BBSome (BBS6, BBS10, and BBS12). Thus, BBS results from a trafficking defect to the cilia membrane [75]. Most of the BBSome cargos are currently unknown but BBS proteins, in particular BBS1, are required for leptin receptor (LepR) signaling in the hypothalamus, and loss of leptin action in POMC neurons due to a defective leptin receptor signaling has been implicated in the obesity phenotype of BBS [75]. Variants of several BBS genes seem to increase susceptibility to obesity in non-BBS patients $[76,77]$, thus exploration of the relevance of BBS proteins for common obesity with regard to leptin receptor trafficking is a worthy effort.

ALS (cone-rod dystrophy, hearing loss, childhood truncal obesity, insulin resistance and hyperinsulinemia, type 2 diabetes, hypertriglyceridemia, short stature in adulthood, cardiomyopathy, and progressive pulmonary, hepatic, and renal dysfunction) and Carpenter (peculiar facies, asymmetry of the skull, polydactyly, brachymesophalangy, mild soft 
tissue syndactyly, obesity, hypogenitalism, congenital heart disease, and ID) syndromes have a unique genetic cause, that is, mutations in the ALMS1 and RAB23 genes, respectively. ALMS1 is a ciliary protein and plays a role in normal centrosome/basal body function and intracellular trafficking events. In the brain, ALMS1 is found widely expressed in most regions including the hypothalamus. The cellular and molecular mechanisms underlying the disorder remain to be understood, and the consequences of centrosome, ciliary, and/or IFT system deficits in the hypothalamic pathways for metabolic abnormalities leading to obesity are not well understood [78]. It has been hypothesized that loss of functioning ALMS1 could impact the cilia on hypothalamic neurons and lead to alteration in behavior and energy homeostasis through abnormal perception of appetite and satiety cues, such as leptin, resulting in overeating and obesity [79]. RAB23 is a member of the Rab family of small GTPases that has been identified along with other Rab GTPases (RAB5, RAB6, RAB8, RAB10, and RAB11) at the primary cilium, which have been shown to function in different ciliary trafficking pathways or processes [74]. Disruption of the ciliary localization or the activities of these Rab GTPases are associated with several ciliopathies due to impairments in cilium formation and function. RAB23 specifically is proposed to act as a negative regulator of hedgehog $(\mathrm{Hh})$ signaling. Thus, the discovery of the genetic basis for Carpenter syndrome [80] provided a link between cilia, Hh signaling, and obesity [81]. Cohen syndrome (CS) (obesity, mental retardation, microcephaly, prominent upper central incisors, and progressive retinochoroidal dystrophy) is caused by autosomal recessive mutations in the VPS13B $(\mathrm{COH} 1)$ gene, which encodes a Golgi matrix protein. The relationship between $\mathrm{COH} 1$ mutations and obesity is not yet understood although altered Golgi integrity and function probably underlie Cohen syndrome [82].

BFLS and MEHMO syndromes are rare X-linked obesity syndromes. The former is characterized by obesity, severe cognitive impairment, epilepsy, hypogonadism, and marked gynecomastia. Mutations in a widely expressed zinc-finger gene, PHF6, at Xq26.3 have been identified in nineteen unrelated cases of BFLS [8]. Although the functional properties of this protein remain unclear, it is localized in the cell nucleus and nucleolus. To date, no single gene has been identified as the genetic cause of MEHMO but the disease locus has been assigned to Xp21.1p22.13 [8]. More recently, truncating mutations in two X-linked genes, $U B E 2 A$ which encodes a ubiquitin-conjugating enzyme and $C U L 4 B$ which encodes a ubiquitin E3 ligase subunit, were identified as causative genes for X-linked mental retardation (XLMR) syndromes associating obesity, seizures, marked hirsutism, and a characteristic facial appearance (UBE2A) [83] or central obesity, aggressive outbursts, relative macrocephaly, hypogonadism, pes cavus, and tremor (CUL4B) [84].

5.1. Chromosomal Syndromes with Obesity. In addition to PWS, several other obesity-related syndromes are caused by chromosomal rearrangements, especially chromosomal deletions. For these syndromes, obesity is usually manifest in many but not all individuals, suggesting reduced penetrance or variable expressivity, or yet that other unidentified factors may be required for the development of the obesity phenotype. Examples include deletions of 1p36 (monosomy 1p36 syndrome), 2q37 (brachydactyly mental retardation syndrome; BDMR), 6q16 (PWS-like syndrome), 9q34 (Kleefstra syndrome), 11p13 (WAGR syndrome), and 17p11.2 (SmithMagenis syndrome; SMS). Such syndromes are generally regarded as contiguous gene disorders although haploinsufficiency for specific genes in the critical interval is likely to be responsible for the phenotypes. Indeed, sequencing of the likely candidate genes mapping to the smallest region of overlap (SRO) for some of these syndromes, following the discovery of atypical and smaller deletions among cases with virtually identical phenotypes, has identified diseasecausative mutations in HDAC4 (2q37), EHMT1 (9q34), and RAI1 (17p11.2) in patients showing strong phenotypic similarity with the known syndromes, but lacking the expected chromosome abnormalities [85-89]. Otherwise, known candidate genes for obesity have been identified in critical map intervals (e.g., SIM1 (6q16), BDNF (11p13)) $[62,64]$. Of note, a number of the chromosome deletions named here show some overlap between them and with PWS in that affected individuals are likely to have childhood obesity, hyperphagia, learning disabilities/DD, hypotonia, and neonatal feeding difficulties. Thus, they often pose significant diagnostic challenges, while having a high likelihood of a shared common underlying mechanism or pathway leading to common phenotypic effects when disrupted [90], raising the possibility that a group of genetically heterogeneous individuals with obesity could be treated if a common molecular etiology was targeted. In this sense, accumulated evidence reveals that diminished BDNF function, which is associated with hyperphagia, obesity, and neurocognitive deficits in both animals and humans, is involved in several of these conditions.

Among a subset of WAGR patients with deletions that included the 11p14 BDNF locus, BDNF haploinsufficiency was associated with lower levels of serum BDNF $(\sim 50 \%$ lower serum BDNF concentration than patients without $B D N F$ deletions) and with a $100 \%$ prevalence of childhoodonset obesity (as compared with $20 \%$ of patients without $B D N F$ deletions) [64]. Likewise, data showed significantly decreased serum BDNF levels in patients with PWS compared with obese controls, which may reflect insufficient central BDNF production [91]. SMS is caused by deletion or mutation (haploinsufficiency) of the retinoic acid induced 1 (RAI1) gene [88]. In addition to $\mathrm{DD} / \mathrm{ID}$, behavioral abnormalities, and sleep disturbances, a majority of children with SMS also have significant early-onset obesity. In a recent model of SMS, expression analysis revealed that Bdnf is downregulated in the hypothalamus of RAI1+/- mice that are obese and hyperphagic due to an impaired satiety response [92]. In addition, reported studies documented RAI1 as a direct (positive) regulator of BDNF expression [92]. Chromosome deletions involving the $2 \mathrm{q} 37$ region result in BDMR syndrome, also known as AHO-like syndrome. BDMR is a complex disorder that presents with a spectrum of 
clinical features, including DD/ID, obesity, autism spectrum disorder, and craniofacial and skeletal abnormalities [93]. Recently, haploinsufficiency of HDAC4 (histone deacetylase 4), which acts as a corepressor for DNA-binding transcription factors, was shown to result in BDMR, and two individuals harboring mutations within the HDAC4 gene were obese/overweight [85]. Data showed that deletion or mutation of HDAC4 results in decreased RAI1 mRNA expression to lower than $50 \%$ levels, indicating that RAI1 may function downstream of HDAC4 and is either directly or indirectly regulated by HDAC4 [85].

Monosomy $1 \mathrm{p} 36$ is the most common terminal deletion syndrome (1/5000 live births). Common features include DD/ID, characteristic dysmorphic features, hypotonia, seizures, hearing loss, heart defects, cardiomyopathy, and behavior abnormalities. Obesity and/or hyperphagia occur in less than $50 \%$ of all cases reported (in one series $15 \%$ of patients exhibited obesity [94]; in another $13 \%$ exhibited hyperphagia [95]). Similar phenotypes are seen among patients with a variety of deletion sizes, and critical regions harboring causative genes for specific features have been difficult to identify. Despite that, genotypephenotype correlations of $1 \mathrm{p} 36$ deletions in five patients with obesity/overweight allowed us to delineate the critical interval to this phenotype between $\sim 2.0$ to $3.0 \mathrm{Mb}$ from the $1 \mathrm{p}$ telomere, with the proximal boundary located to the proto-oncogene SKI [96]. A subsequent study by Rosenfeld et al. [97] further narrowed this critical interval to a $500 \mathrm{~kb}$ region ( $\sim 1.7$ to $2.3 \mathrm{Mb}$ from the telomere) containing eight genes (GNB1, CALML6, TMEM52, C1ORF222, KIAA1751, GABRD, PRKCZ, and SKI), based on the smallest $1 \mathrm{p} 36$ deletion reported in the literature with hyperphagia. Among these, GNB1 encodes a G-protein subunit that is ubiquitously expressed and is likely involved in signal transduction in neurons; TMEM52, C1ORF222, and KIAA1751 are expressed during embryonic development and show expression in the brain; GABRD, PRKCZ, and SKI are candidate genes for the neurologic features associated with monosomy $1 \mathrm{p} 36$.

Deletion 6q16 syndrome is a PWS-like syndrome characterized by obesity, hyperphagia, hypotonia, small hands and feet, eye/vision anomalies, and global DD [62]. Until recently, there were only five patients with overlapping interstitial 6q16 deletions and a PWS-like phenotype characterized with high resolution techniques, which allowed narrowing of the SRO for the presumed gene(s) involved in the PWS-like features to $4.1 \mathrm{Mb}$ located at 6q16.1q16.2 [62]. The SIM1 gene, which appears to function downstream of the leptin-melanocortin signaling pathway to control appetite [14] and is implicated with early-onset obesity in a patient with a balanced translocation which disrupts SIM1 [61], lies within this interval and is likely responsible for obesity in these patients. An additional four individuals with a PWS-like phenotype and overlapping 6q15q22.2 deletions were recently described [98], and only two had deletions of SIM1. Thus, other genes on 6q may contribute to this phenotype, including a newly proposed candidate, the transcription cofactor gene VGLL2 (vestigial like 2) on 6q22.2, which has strong expression in the developing mice ventromedial hypothalamus (VMH); rats with $\mathrm{VMH}$ lesion demonstrate extreme hyperphagia.

Deletions of the $9 \mathrm{q} 34.3$ subtelomeric region encompassing the EHMT1 (euchromatic histone methyltransferase 1) gene, or loss-of-function mutations in EHMT1, result in a clinically recognizable syndrome that is characterized by specific craniofacial features, hypotonia, childhood obesity, microcephaly, substantial speech delay, and ID [99]. The true incidence of obesity is unknown, but several patients with either deletion or mutation of the EHMT1 gene have been reported as obese, and some with increased appetite and food seeking behaviour [100]. In one series $45 \%$ of patients with EHMT1 mutations were overweight [101]. EHMT1, which encodes a histone methyltransferase, plays a role in the control of gene transcription through epigenetic modification of chromatin structure.

\subsection{Array Genomic Hybridization in Syndromic Forms of} Obesity. While obesity is known to be associated with several genomic disorders known to result from CNVs (Table 1), array genomic hybridization in patients with obesity syndromes where the genetic causes are unknown has afforded discovery opportunities for CNVs that have not previously been detectable. For example, chromosome 1p21.3 microdeletions comprising DPYD and MIR137 were associated with ID and (tendency) to overweight [102]; overlapping deletions of $2 \mathrm{p} 25.3$ comprising MYT1L were associated with ID and obesity/overweight [103]; deletions of a $4.2 \mathrm{Mb}$ region at $6 \mathrm{q} 14.1 \mathrm{q} 15$ containing the genes HTR $1 E$, ME1, CYB5R4, and SNX14 were associated with obesity, $\mathrm{DD}$, and a distinctive clinical phenotype (such as motor delay, hernia, rounded face with full cheeks, epicanthal folds, short palpebral fissures, bulbous nose, large ears, and 2-3 toe syndactyly) [104]; deletions of a $2.3 \mathrm{Mb}$ region on $11 \mathrm{p} 14.1$ including the BDNF were associated with DD, behavioral problems, and obesity [105]; duplications of 19q12q13.2 containing the genes AKT2, CEACAM1, CEBPA, LIPE, and $T G F B 1$, which are involved in adipose tissue homeostasis and insulin resistance, were described in three patients who displayed DD and obesity [106] (Table 1). Chromosome rearrangements from individuals with syndromic obesity reported in the literature have been extensively reviewed by others [107].

DECIPHER is an interactive web-based resource and database of array genomic hybridization data that catalogues genomic rearrangements and clinical characteristics from patients suffering from developmental disorders, contributed by an international community of academic departments of clinical genetics. There are 189 entries matching the term obesity in the DECIPHER database as of July 2012. We compiled a list of 54 de novo CNVs (or familial inherited from a parent with similar phenotype to child), thus more likely to be classified as pathogenic, that might represent novel genomic rearrangements playing a role in obesity development (Table 2).

In recent years, the ability to identify CNVs using many technology platforms available for array genomic hybridization (e.g., oligonucleotide- or SNP-based arrays) 
TABLE 1: Genomic regions encompassing genes involved in the development of obesity and developmental delay/intellectual disability.

\begin{tabular}{|c|c|c|c|c|}
\hline \multicolumn{5}{|c|}{ Known genomic disorder regions associated with obesity } \\
\hline Chr & Loci & Gene $(s)^{\mathrm{a}}$ & Phenotype & OMIM \\
\hline chr1 & $1 \mathrm{p} 36$ & $G A B R D$ & Chromosome 1 p36 deletion syndrome & 607872 \\
\hline chr2 & $2 \mathrm{q} 37$ & HDAC4 & BDMR syndrome & 600430 \\
\hline chr6 & $6 q 16$ & SIM1 & Obesity, severe & 603128 \\
\hline chr9 & $9 q 34$ & EHMT1 & Kleefstra syndrome & 610253 \\
\hline chr11 & $11 \mathrm{p} 13$ & WT1, PAX6 & WAGR syndrome & 194072 \\
\hline chr15 & $15 \mathrm{q} 11.2$ & NDN, SNRPN & Prader-Willi syndrome & 176270 \\
\hline $\operatorname{chr} 16$ & $16 \mathrm{p} 11.2$ & SH2B1 & Chromosome $16 \mathrm{p} 11.2$ deletion syndrome, $220 \mathrm{~kb}$ & 613444 \\
\hline chr16 & $16 \mathrm{p} 11.2$ & TBX6 & Chromosome 16p11.2 deletion syndrome, $593 \mathrm{~kb}$ & 611913 \\
\hline chr17 & $17 \mathrm{p} 11.2$ & RAI1 & Smith-Magenis syndrome & 182290 \\
\hline \multicolumn{5}{|c|}{ Novel CNV loci playing a role in obesity } \\
\hline Chr & loci & $\operatorname{Gene}(s)^{\mathrm{a}}$ & Phenotype & Refs \\
\hline Chr1 & $1 \mathrm{p} 21.3$ & DPYD, MIR137 & Deletions associated with ID and (tendency) to overweight & {$[102]$} \\
\hline Chr2 & $2 \mathrm{p} 25.3$ & MYT1L & Deletions associated with ID and obesity/overweight & {$[103]$} \\
\hline Chr6 & $6 \mathrm{q} 14 \mathrm{q} 15$ & HTR1E, ME1, CYB5R4, SNX14 & $\begin{array}{l}\text { Deletions Associated with DD, obesity, and a distinct } \\
\text { clinical phenotype }\end{array}$ & {$[104]$} \\
\hline Chr6 & $6 \mathrm{q} 22$ & VGLL2 & Less penetrant locus for a PWS-like phenotype & {$[98]$} \\
\hline Chr11 & $11 \mathrm{p} 14.1$ & $B D N F$ & Deletions associated with ADHD, DD, autism, and obesity & [105] \\
\hline Chr19 & $19 q 12 q 13.2$ & AKT2, CEACAM1, CEBPA, LIPE, TGFB1 & Duplications described in patients with DD and obesity & [106] \\
\hline
\end{tabular}

All coordinates are according to build36. Chr.: chromosome; OMIM: Online Mendelian Inheritance in Man; Refs: references.

a Potential candidate genes for the syndrome phenotype and/or obesity or identifiers of the genomic locations.

has facilitated the identification of several new microdeletion or microduplication syndromes, in addition to refining the critical interval (or dosage-sensitive region) of known genomic disorders [53]. These technologies have been used particularly in large cohort studies with a general diagnosis of intellectual and developmental disabilities (with an average diagnostic yield of $12.2 \%$ ) and are now recommended as first-tier genetic tests for the evaluation of this patient population $[108,109]$, but the overall diagnostic yield of array in patients with syndromic forms of obesity has not been established. Although several well-known syndromic forms associate remarkable features allowing to establish or suspect a clinical diagnosis, which can be confirmed by other targeted assays (e.g., FISH, quantitative PCR (qPCR), multiplex ligation-dependent probe amplification (MLPA), and targeted mutation screening of the corresponding candidate genes), in many cases patients lack sufficient specific history or features from physical examination. Furthermore, any of the genes involved in mutational events can still be involved in a CNV, as demonstrated in one study in which oligonucleotide array CGH detected a homozygous $80 \mathrm{~kb}$ deletion in the chromosomal $1 \mathrm{p} 31.3$ region, comprising $D N A J 6 C$ and $L E P R$, in a 7-year-old patient with early-onset obesity, ID, and epilepsy, and thus confirming the effect of deleterious mutations in the leptin receptor [110]. In another instance, oligonucleotide arrays allowed the detection of intragenic heterozygous deletions in the $\mathrm{COH} 1$ gene in three patients with atypical phenotype of Cohen syndrome, and subsequent sequencing of the $\mathrm{COH} 1$ gene revealed point mutations in the second allele in all three patients [111]. Thus, high-resolution arrays can still be used to identify autosomal recessive syndromes, especially in the context of a contiguous gene syndrome (as deletions in neighboring genes may affect the phenotype), and to further extend the phenotypic and mutational spectrum of recessive disorders.

\section{Future Perspectives}

The extensive genetic heterogeneity of obesity and significant clinical overlap between obesity syndromes have been major problems for molecular diagnostic and genetic counseling applications. While there have been several studies regarding the use of array CGH among individuals with DD/ID, ASDs, and multiple congenital anomalies, the use of array $\mathrm{CGH}$ in clinical practice using obesity (in the presence of other anomalies) as an initial paradigm has not been yet systematically explored. Array genomic hybridization allows the detection of known abnormalities and the investigation of hitherto unknown abnormalities. Besides revealing the genetic basis of obesity and associate phenotypes in selected individuals, such an effort will allow the phenotypic description of new obesity-related syndromes and define previously unidentified genomic regions or genes involved in the development of obesity thus enhancing our understanding of obesogenic pathways. These data will provide a useful list of genomic regions or genes that are worth to investigate further experimentally and will also help developing new diagnostic arrays, such as targeted oligonucleotide arrays, or specifically an exon-targeted clinical array to detect deletions or duplications occurring within genes in which the dosage effect is known or suspected to cause the phenotype as 
TABLE 2: CNVs in the DECIPHER database likely to play a role in obesity.

\begin{tabular}{|c|c|c|c|}
\hline Chr & Genomic rearrangements ${ }^{\mathrm{a}}$ & Phenotype(s) & $\begin{array}{l}\text { DECIPHER } \\
\text { ID } \\
\end{array}$ \\
\hline \multirow[t]{2}{*}{ Chr1 } & $\begin{array}{l}\text { arr 1q12q21.1(141,959,285-147,024,032)x3-inherited } \\
\text { (overlap the TAR syndrome and 1q21.1 recurrent } \\
\text { microdeletion/microduplication locus) }\end{array}$ & $\begin{array}{l}\text { high birth weight ( }>90 \text { th centile) } \\
\text { and } 5 \text { other phenotypes }\end{array}$ & 265628 \\
\hline & arr 1q31.1q31.2(187,292,321-191,478,235)x3 dn & $\begin{array}{l}\text { obesity, general abnormalities, and } 7 \\
\text { other phenotypes }\end{array}$ & 3463 \\
\hline \multirow{3}{*}{ Chr2 } & arr $2 \mathrm{p} 25.3(53,452-3,194,600) \times 1 \mathrm{dn}$ & $\begin{array}{l}\text { obesity, generalized abnormalities, and } 7 \\
\text { other phenotypes }\end{array}$ & 258576 \\
\hline & arr 2p24.1p23.3(23,826,350-24,923,855)x1-inherited & $\begin{array}{l}\text { generalized obesity and } 4 \text { other } \\
\text { phenotypes }\end{array}$ & 255430 \\
\hline & arr 2q31.1(170,471,086-175,231,429)x1 dn & $\begin{array}{l}\text { generalized obesity and } 19 \text { other } \\
\text { phenotypes }\end{array}$ & 250211 \\
\hline \multirow{3}{*}{ Chr3 } & arr $3 p 26.3(768,376-2,367,266) \times 1 \mathrm{dn}$ & truncal obesity and 5 other phenotypes & 249965 \\
\hline & arr 3q13.2-q13.31(113,681,019-116,466,222)x1 dn & truncal obesity and 3 other phenotypes & 4673 \\
\hline & $\operatorname{arr} 3 \mathrm{q} 13.31 \mathrm{q} 21.2(116,885,009-125,066,880) \times 1 \mathrm{dn}$ & truncal obesity and 5 other phenotypes & 251079 \\
\hline Chr4 & arr 4q21.21q21.23(82,301,439-85,425,757)x1 dn & $\begin{array}{l}\text { high birth weight (>90th centile) and } 17 \\
\text { other phenotypes }\end{array}$ & 4539 \\
\hline \multirow{4}{*}{ Chr5 } & arr 5p15.2p14.1(12,337,356-27,024,241)x1 dn & $\begin{array}{l}\text { obesity, general abnormalities, and } 3 \\
\text { other phenotypes }\end{array}$ & 250008 \\
\hline & arr 5p13.2p13.1(35,624,846-39,364,263)x3 dn & $\begin{array}{l}\text { generalized obesity and } 26 \text { other } \\
\text { phenotypes }\end{array}$ & 255925 \\
\hline & $\operatorname{arr} 5 q 14.3 q 15(90,230,044-94,799,167) \times 1 \mathrm{dn}$ & truncal obesity and 8 other phenotypes & 248692 \\
\hline & $\operatorname{arr} 5 q 23 \cdot 1 \mathrm{q} 23 \cdot 2(116,801,735-124,680,789) \times 1 \mathrm{dn}$ & $\begin{array}{l}\text { truncal obesity and } 3 \text { other } \\
\text { phenotypes }\end{array}$ & 261304 \\
\hline Chr6 & arr 6q14.1q15(79,381,580-88,100,133)x1 dn & $\begin{array}{l}\text { obesity, general abnormalities, and } 18 \\
\text { other phenotypes }\end{array}$ & 1878 \\
\hline \multirow{3}{*}{ Chr7 } & $\begin{array}{l}\text { arr 7q11.23(72,364,514-73,777,326)x3 dn (overlap } \\
\text { WBS locus; GTF2I) }\end{array}$ & $\begin{array}{l}\text { generalized obesity and } 17 \text { other } \\
\text { phenotypes }\end{array}$ & 255467 \\
\hline & $\operatorname{arr} 7 q 22.1 q 22.2(102,145,556-105,274,891) \times 1 ~ d n$ & $\begin{array}{l}\text { obesity, general abnormalities, } \\
\text { and } 2 \text { other phenotypes }\end{array}$ & 625 \\
\hline & arr 7q22.1q22.3(103,887,195-106,790,044)x1 dn & $\begin{array}{l}\text { high birth weight ( }>90 \text { th centile) and } 6 \\
\text { other phenotypes }\end{array}$ & 4470 \\
\hline \multirow{2}{*}{ Chr8 } & $\begin{array}{l}\text { arr 8p23.1(6,986,631-12,285,366)x3 dn } \\
\text { (overlap 8p23.1 deletion/duplication syndrome; SOX7, } \\
\text { CLDN23) }\end{array}$ & $\begin{array}{l}\text { generalized obesity and } 9 \text { other } \\
\text { phenotypes }\end{array}$ & 255954 \\
\hline & $\operatorname{arr} 8 \mathrm{q} 12.1(58,181,408-59,144,674) \times 1 \mathrm{dn}$ & $\begin{array}{l}\text { generalized obesity and } 4 \text { other } \\
\text { phenotypes }\end{array}$ & 260283 \\
\hline \multirow{3}{*}{ Chr9 } & arr 9q21.11(70,791,222-71,030,800)x3-inherited & $\begin{array}{l}\text { generalized obesity and } 2 \text { other } \\
\text { phenotypes }\end{array}$ & 251354 \\
\hline & $\operatorname{arr} 9 q 22.32 q 22.33(96,375,866-101,058,940) \times 1 \mathrm{dn}$ & $\begin{array}{l}\text { high birth weight ( }>90 \text { th centile) } \\
\text { and } 11 \text { other phenotypes }\end{array}$ & 1002 \\
\hline & arr 9q33.3q34.11(128,990,000-130,220,000)x1 dn & $\begin{array}{l}\text { generalized obesity and } 4 \text { other } \\
\text { phenotypes }\end{array}$ & 259586 \\
\hline \multirow{3}{*}{ Chr12 } & arr 12q13.12q13.13(51,293,317-54,455,978)x3 dn & truncal obesity and 12 other phenotypes & 248785 \\
\hline & arr 12q21.1q25(68,841,926-71,439,458)x1 dn & $\begin{array}{l}\text { obesity, general abnormalities, } \\
\text { and } 10 \text { other phenotypes }\end{array}$ & $258580 / 258581$ \\
\hline & arr 12q21.32q23.1(87,208,712-99,988,990)x3 dn & $\begin{array}{l}\text { obesity, general abnormalities, } \\
\text { and } 12 \text { other phenotypes }\end{array}$ & 258582 \\
\hline \multirow[t]{2}{*}{ Chr13 } & arr 13q13.3q14.11(38,442,447-41,548,237)x1 dn & $\begin{array}{l}\text { high birth weight (>90th centile) and } 23 \\
\text { other phenotypes }\end{array}$ & 1304 \\
\hline & arr 13q32.3q32.3(100,431,907-100,838,153)x1 dn & truncal obesity and 6 other phenotypes & 2130 \\
\hline
\end{tabular}


TABle 2: Continued.

\begin{tabular}{|c|c|c|c|}
\hline Chr & Genomic rearrangements ${ }^{\mathrm{a}}$ & Phenotype(s) & $\begin{array}{l}\text { DECIPHER } \\
\text { ID }\end{array}$ \\
\hline \multirow{2}{*}{ Chr14 } & arr 14q11.2(20,314,536-21,320,719)x3 dn & $\begin{array}{l}\text { obesity, general abnormalities, and } 15 \\
\text { other phenotypes }\end{array}$ & 258583 \\
\hline & arr 14q23.1 $(56,291,177-57,664,121) \times 1 \mathrm{dn}$ & $\begin{array}{l}\text { generalized obesity and } 8 \text { other } \\
\text { phenotypes }\end{array}$ & 255207 \\
\hline \multirow[b]{2}{*}{ Chr15 } & arr 15q14q15.3(39,072,646-43,613,803)x1 dn & truncal obesity and 5 other phenotypes & 1392 \\
\hline & $\begin{array}{l}\text { arr 15q26.2q26.3( } 95,128,043-100,168,718) \times 1 \mathrm{dn} \\
\text { (overlap 15q26 overgrowth syndrome) }\end{array}$ & truncal obesity and 3 other phenotypes & 2502 \\
\hline \multirow{3}{*}{ Chr16 } & $\begin{array}{l}\text { arr 16p13.11(14,993,254-16,189,808)x3 dn (overlap } \\
16 \text { p13.1 } 1 \text { deletion and duplication syndrome; MYH11) }\end{array}$ & $\begin{array}{l}\text { generalized obesity and } 10 \text { other } \\
\text { phenotypes }\end{array}$ & 2370 \\
\hline & arr 16q12.1q21(49,499,378-57,740,601)x3 dn & $\begin{array}{l}\text { generalized obesity and } 9 \text { other } \\
\text { phenotypes }\end{array}$ & 248877 \\
\hline & arr $16 \mathrm{q} 24.2 \mathrm{q} 24.3(85,897,636-87,862,929) \times 1 \mathrm{dn}$ & $\begin{array}{l}\text { generalized obesity and } 8 \text { other } \\
\text { phenotypes }\end{array}$ & 255327 \\
\hline \multirow{6}{*}{ Chr17 } & arr $17 \mathrm{p} 13.2(5,537,212-6,197,315) \times 1$-inherited & $\begin{array}{l}\text { generalized obesity and } 8 \text { other } \\
\text { phenotypes }\end{array}$ & 254050 \\
\hline & arr $17 \mathrm{p} 13 \cdot 1(6,896,836-7,157,572) \times 3 \mathrm{dn}$ & $\begin{array}{l}\text { generalized obesity and } 5 \text { other } \\
\text { phenotypes }\end{array}$ & 258588 \\
\hline & arr 17p13.1(6,920,991-7,767,844)x3 dn & $\begin{array}{l}\text { generalized obesity and } 10 \text { other } \\
\text { phenotypes }\end{array}$ & 262186 \\
\hline & arr 17p13.1 $(6,972,362-7,490,406) \times 3 \mathrm{dn}$ & $\begin{array}{l}\text { generalized obesity and } 24 \text { other } \\
\text { phenotypes }\end{array}$ & 256668 \\
\hline & $\begin{array}{l}\text { arr 17q11.2(26,085,851-27,391,269)x3 dn (overlap NF1 } \\
\text { deletion syndrome) }\end{array}$ & $\begin{array}{l}\text { generalized obesity and } 4 \text { other } \\
\text { phenotypes }\end{array}$ & 256904 \\
\hline & $\begin{array}{l}\text { arr 17q21.31(41,288,423-41,528,254)x3 dn (overlap } \\
17 \mathrm{q} 21.31 \text { deletion/duplication; MAPT) }\end{array}$ & $\begin{array}{l}\text { high birth weight ( }>90 \text { th centile) and } 7 \\
\text { other phenotypes }\end{array}$ & 249014 \\
\hline \multirow{2}{*}{ Chr19 } & arr 19p13.12(14,243,780-15,353,848)x1 dn & $\begin{array}{l}\text { generalized obesity and } 15 \text { other } \\
\text { phenotypes }\end{array}$ & 255743 \\
\hline & arr 19q13.43(58,605,464-59,010,255)x1 dn & $\begin{array}{l}\text { generalized obesity and } 7 \text { other } \\
\text { phenotypes }\end{array}$ & 2590 \\
\hline \multirow[b]{2}{*}{ Chr20 } & arr 20p13(17,408-1,810,420)x3 dn & truncal obesity and 22 other phenotypes & 250961 \\
\hline & arr 20p12.1(14,556,853-14,704,918)x1 dn & $\begin{array}{l}\text { obesity, general abnormalities, and } 4 \\
\text { other phenotypes }\end{array}$ & 249098 \\
\hline \multirow{2}{*}{ Chr22 } & $\begin{array}{l}\text { arr 22q11.21(20,129,773-21,984,237)x1 dn (overlap } \\
\text { DG/VCFS, and 22q11.2 distal deletion syndrome) }\end{array}$ & truncal obesity and 6 other phenotypes & 248709 \\
\hline & $\begin{array}{l}\text { arr 22q11.21q11.22(20,247,200-21,293,000)x1 dn } \\
\text { (overlap 22q11.2 distal deletion syndrome; BCR, } \\
\text { MAPK1) }\end{array}$ & $\begin{array}{l}\text { obesity, general abnormalities, and } 4 \\
\text { other phenotypes }\end{array}$ & 250888 \\
\hline \multirow{7}{*}{ ChrX } & arr Xp22.13p22.12(18,123,941-19,743,555)x1 dn & $\begin{array}{l}\text { obesity, general abnormalities and } 6 \\
\text { other phenotypes }\end{array}$ & 258585 \\
\hline & arr Xp11.4p11.3(42,241,552-43,449,256)x1-inherited & $\begin{array}{l}\text { generalized obesity and } 3 \text { other } \\
\text { phenotypes }\end{array}$ & 258161 \\
\hline & $\begin{array}{l}\text { arr Xp11.23(48,639,178-48,956,107)x1 dn (overlap } \\
\text { Xp11.22p11.23 microduplication) }\end{array}$ & $\begin{array}{l}\text { obesity, general abnormalities, } \\
\text { and } 4 \text { other phenotypes }\end{array}$ & 254343 \\
\hline & $\begin{array}{l}\text { arr Xq22.11q22.3(101,252,518-105,733,692)x1 dn } \\
\text { (overlap Pelizaeus-Merzbacher disease) }\end{array}$ & $\begin{array}{l}\text { high birth weight (>90th centile), and } 21 \\
\text { other phenotypes }\end{array}$ & 257182 \\
\hline & arr Xq27.2(140,225,865-140,521,032)x1 dn & $\begin{array}{l}\text { generalized obesity and } 2 \text { other } \\
\text { phenotypes }\end{array}$ & 250330 \\
\hline & arr Xq27.3q28 $(144,934,242-148,461,832) \times 1 \mathrm{dn}$ & $\begin{array}{l}\text { obesity, general abnormalities, } \\
\text { and } 10 \text { other phenotypes }\end{array}$ & 250246 \\
\hline & arr Xq27.3q28(145,354,647-148,617,309)x1 dn & $\begin{array}{l}\text { generalized obesity and } 2 \text { other } \\
\text { phenotypes }\end{array}$ & 265618 \\
\hline
\end{tabular}

All coordinates are according to build36. Chr.: chromosome; ID: identification; TAR: Thrombocytopenia with absent radius; WBS: Williams-Beuren syndrome.

aAfter excluding CNVs within known genomic disorder regions associated with obesity, CNVs inherited from phenotypically normal parents or with inheritance status unknown, and cases in DECIPHER with more than one variants reported. 
well as to infer a higher risk of inherited obesity. These technologies are likely to be used for $\mathrm{CNV}$ detection for some time while structural variation is still challenging to assess using only next-generation sequencing- (NGS-) based strategies. In addition, the informatics resources needed for whole genome/exome sequencing data analysis and storage are considerably and can often be a limitation. Alternatively, target enrichment approaches coupled with NGS have been developed for efficient mutation detection of patients with diseases showing high genetic heterogeneity [112]. These strategies have allowed the reliable detection of causative mutations in patients without previous molecular diagnosis. Similarly, all candidate genes located in CNV intervals implicated in syndromic forms of obesity may be included in a targeted capture strategy for identification of mutations and other potentially pathogenic variants in patients without previously known molecular diagnosis. The availability of DNA microarrays and NGS technology as complimentary approaches provides patients with comprehensive mutation analysis and will ultimately help in developing a NGS protocol relevant to clinical practice. Identifying genes or molecular pathways common to the obesity phenotype seen in individuals with rare obesity-related disorders and those non-syndromic individuals from the general population may lead in the future to new therapeutic options for each syndrome and obesity in general.

\section{Acknowledgments}

This work was supported by the State of Sao Paulo Research Foundation, FAPESP (09/52523-1 to C. S. D'Angelo); The Centers for Research, Innovation, and Diffusion, CEPIDFAPESP (1998/14254-2) and the National Council for Scientific and Technological Development, CNPq (304381/2007-1 to C. P. Koiffmann).

\section{References}

[1] World Health Organization, "Physical status: the use and interpretation of anthropometry," Report of a WHO Expert Committee, Technical Report Series, 854, World Health Organization, Geneva, Switzerland, 1995.

[2] National Institutes of Health, "Clinical guidelines on the identification, evaluation, and treatment of overweight and obesity in adults: the evidence report," Obesity Research, vol. 6, supplement 2, pp. 51S-209S, 1998.

[3] National Institutes of Health, "Erratum: clinical guidelines on the identification, evaluation, and treatment of overweight and obesity in adults: the evidence report," Obesity Research, vol. 6, no. 6, article 464, 1998.

[4] B. Swinburn, G. Egger, and F. Raza, "Dissecting obesogenic environments: the development and application of a framework for identifying and prioritizing environmental interventions for obesity," Preventive Medicine, vol. 29, no. 6, pp. 563-570, 1999.

[5] A. J. Stunkard, T. T. Foch, and Z. Hrubec, "A twin study of human obesity," Journal of the American Medical Association, vol. 256, no. 1, pp. 51-54, 1986.

[6] H. H. M. Maes, M. C. Neale, and L. J. Eaves, "Genetic and environmental factors in relative body weight and human adiposity," Behavior Genetics, vol. 27, no. 4, pp. 325-351, 1997.

[7] S. A. Ranadive and C. Vaisse, "Lessons from extreme human obesity: monogenic disorders," Endocrinology and Metabolism Clinics of North America, vol. 37, no. 3, pp. 733$751,2008$.

[8] A. Goldstone and P. Beales, "Genetic obesity syndromes," Frontiers of Hormone Research, vol. 36, pp. 37-60, 2007.

[9] P. R. Beales, I. S. Farooqi, and S. O'Rahilly, Genetics of Obesity Syndromes, Oxford University Press, New York, NY, USA, 2009.

[10] E. Kousta, C. G. Hadjiathanasiou, G. Tolis, and A. Papathanasiou, "Pleiotropic genetic syndromes with developmental abnormalities associated with obesity," Journal of Pediatric Endocrinology and Metabolism, vol. 22, no. 7, pp. 581-592, 2009.

[11] J. V. Neel, "Diabetes mellitus: a "thrifty" genotype rendered detrimental by "progress"?" American Journal of Human Genetics, vol. 14, pp. 353-362, 1962.

[12] C. G. Bell, A. J. Walley, and P. Froguel, "The genetics of human obesity," Nature Reviews Genetics, vol. 6, no. 3, pp. 221-234, 2005.

[13] A. J. Walley, J. E. Asher, and P. Froguel, "The genetic contribution to non-syndromic human obesity," Nature Reviews Genetics, vol. 10, no. 7, pp. 431-442, 2009.

[14] S. Ramachandrappa and I. S. Farooqi, "Genetic approaches to understanding human obesity," Journal of Clinical Investigation, vol. 121, no. 6, pp. 2080-2086, 2011.

[15] L. A. Hindorff, P. Sethupathy, H. A. Junkins et al., "Potential etiologic and functional implications of genome-wide association loci for human diseases and traits," Proceedings of the National Academy of Sciences of the United States of America, vol. 106, no. 23, pp. 9362-9367, 2009.

[16] F. R. Day and R. J. F. Loss, "Developments in obesity genetics in the era of genome-wide association studies," Journal of Nutrigenetics and Nutrigenomics, vol. 4, pp. 222-238, 2011.

[17] E. K. Speliotes, C. J. Willer, S. I. Berndt et al., "Association analyses of 249, 796 individuals reveal 18 new loci associated with body mass index," Nature Genetics, vol. 42, pp. 937-948, 2010.

[18] H. Choquet and D. Meyre, "Molecular basis of obesity: current status and future prospects," Current Genomics, vol. 12, no. 3, pp. 154-168, 2011.

[19] W. W. Cheung and P. Mao, "Recent advances in obesity: genetics and beyond," ISRN Endocrinology, vol. 2012, Article ID 536905, 2012.

[20] Y. C. L. Tung and G. S. H. Yeo, "From GWAS to biology: lessons from FTO," Annals of the New York Academy of Sciences, vol. 1220, no. 1, pp. 162-171, 2011.

[21] P. M. Schmid, I. Heid, C. Buechler et al., "Expression of fourteen novel obesity-related genes in zucker diabetic fatty rats," Cardiovascular Diabetology, vol. 11, article 48, 2012.

[22] S. P. Dickson, K. Wang, I. Krantz, H. Hakonarson, and D. B. Goldstein, "Rare variants create synthetic genome-wide associations," PLoS Biology, vol. 8, no. 1, Article ID e1000294, 2010.

[23] C. A. Anderson, N. Soranzo, E. Zeggini, and J. C. Barrett, "Synthetic associations are unlikely to account for many common disease genome-wide association signals," PLoS Biology, vol. 9, no. 1, Article ID e1000580, 2011.

[24] A. Scherag, I. Jarick, J. Grothe et al., "Investigation of a genome wide association signal for obesity: synthetic association and haplotype analyses at the melanocortin 4 
receptor gene locus," PLoS ONE, vol. 5, no. 11, Article ID e13967, 2010.

[25] T. A. Manolio, F. S. Collins, N. J. Cox et al., "Finding the missing heritability of complex diseases," Nature, vol. 461, no. 7265, pp. 747-753, 2009.

[26] E. T. Cirulli and D. B. Goldstein, "Uncovering the roles of rare variants in common disease through whole-genome sequencing," Nature Reviews Genetics, vol. 11, no. 6, pp. 415425, 2010.

[27] J. Yang, T. A. Manolio, L. R. Pasquale et al., "Genome partitioning of genetic variation for complex traits using common SNPs," Nature Genetics, vol. 43, no. 6, pp. 519-525, 2011.

[28] A. J. Iafrate, L. Feuk, M. N. Rivera et al., "Detection of largescale variation in the human genome," Nature Genetics, vol. 36, no. 9, pp. 949-951, 2004.

[29] J. Sebat, B. Lakshmi, J. Troge et al., "Large-scale copy number polymorphism in the human genome," Science, vol. 305, no. 5683, pp. 525-528, 2004.

[30] R. Redon, S. Ishikawa, K. R. Fitch et al., "Global variation in copy number in the human genome," Nature, vol. 444, no. 7118, pp. 444-454, 2006.

[31] P. Stankiewicz and J. R. Lupski, "Structural variation in the human genome and its role in disease," Annual Review of Medicine, vol. 61, pp. 437-455, 2010.

[32] J. R. Lupski, "Genomic disorders: structural features of the genome can lead to DNA rearrangements and human disease traits," Trends in Genetics, vol. 14, no. 10, pp. 417-422, 1998.

[33] J. R. Lupski, "Genomic disorders ten years on," Genome Medicine, vol. 1, no. 4, article 42, 2009.

[34] D. F. Conrad, C. Bird, B. Blackburne et al., "Mutation spectrum revealed by breakpoint sequencing of human germline CNVs," Nature Genetics, vol. 42, no. 5, pp. 385-391, 2010.

[35] S. A. McCarroll, F. G. Kuruvilla, J. M. Korn et al., "Integrated detection and population-genetic analysis of SNPs and copy number variation," Nature Genetics, vol. 40, no. 10, pp. 11661174, 2008.

[36] N. Craddock, M. E. Hurles, N. Cardin et al., "Genome-wide association study of CNVs in 16,000 cases of eight common diseases and 3,000 shared controls," Nature, vol. 464, pp. 713$720,2010$.

[37] L. A. Hindorff, P. Sethupathy, H. A. Junkins et al., "Potential etiologic and functional implications of genome-wide association loci for human diseases and traits," Proceedings of the National Academy of Sciences of the United States of America, vol. 106, no. 23, pp. 9362-9367, 2009.

[38] The ENCODE Project Consortium, "An integrated encyclopedia of DNA elements in the human genome," Nature, vol. 489, pp. 57-74, 2012.

[39] C. J. Willer, E. K. Speliotes, R. J. Loos et al., "Six new loci associated with body mass index highlight a neuronal influence on body weight regulation," Nature Genetics, vol. 41, pp. 25-34, 2009.

[40] B. Y. Sha, T. L. Yang, L. J. Zhao et al., "Genome-wide association study suggested copy number variation may be associated with body mass index in the Chinese population," Journal of Human Genetics, vol. 54, no. 4, pp. 199-202, 2009.

[41] I. Jarick, C. I. Vogel, S. Scherag et al., "Novel common copy number variation for early onset extreme obesity on chromosome 11q11 identified by a genome-wide analysis," Human Molecular Genetics, vol. 20, no. 4, Article ID ddq518, pp. 840-852, 2011.
[42] G. Gibson, "Rare and common variants: twenty arguments," Nature Reviews Genetics, vol. 13, pp. 135-145, 2011.

[43] E. G. Bochukova, N. Huang, J. Keogh et al., "Large, rare chromosomal deletions associated with severe early-onset obesity," Nature, vol. 463, no. 7281, pp. 666-670, 2010.

[44] R. G. Walters, S. Jacquemont, A. Valsesia et al., "A new highly penetrant form of obesity due to deletions on chromosome 16p11. 2," Nature, vol. 463, pp. 671-675, 2010.

[45] K. Wang, W. D. Li, J. T. Glessner, S. F. A. Grant, H. Hakonarson, and R. A. Price, "Large copy-number variations are enriched in cases with moderate to extreme obesity," Diabetes, vol. 59, no. 10, pp. 2690-2694, 2010.

[46] J. T. Glessner, J. P. Bradfield, K. Wang et al., "A genome-wide study reveals copy number variants exclusive to childhood obesity cases," American Journal of Human Genetics, vol. 87, no. 5, pp. 661-666, 2010.

[47] D. Zhang, Y. Qian, N. Akula et al., "Accuracy of CNV detection from GWAS data," PLoS ONE, vol. 6, no. 1, Article ID e14511, 2011.

[48] N. E. Wineinger and H. K. Tiwari, "The impact of errors in copy number variation detection algorithms on association results," PLoS ONE, vol. 7, no. 4, Article ID e32396, 2012.

[49] S. Girirajan, J. A. Rosenfeld, G. M. Cooper et al., "A recurrent 16 p12.1 microdeletion supports a two-hit model for severe developmental delay," Nature Genetics, vol. 42, pp. 203-209, 2010.

[50] S. Girirajan and E. E. Eichler, "Phenotypic variability and genetic susceptibility to genomic disorders," Human Molecular Genetics, vol. 19, no. 2, pp. R176-R187, 2010.

[51] J. A. Veltman and H. G. Brunner, "Understanding variable expressivity in microdeletion syndromes," Nature Genetics, vol. 42, no. 3, pp. 192-193, 2010.

[52] E. B. Kaminsky, V. Kaul, J. Paschall et al., "An evidence-based approach to establish the functional and clinical significance of copy number variants in intellectual and developmental disabilities," Genetics in Medicine, vol. 13, pp. 777-784, 2011.

[53] G. M. Cooper, B. P. Coe, S. Girirajan et al., "A copy number variation morbidity map of developmental delay," Genetics in Medicine, vol. 43, pp. 838-846, 2011.

[54] R. Bachmann-Gagescu, H. C. Mefford, C. Cowan et al., "Recurrent 200-kb deletions of 16 p11.2 that include the SH2B1 gene are associated with developmental delay and obesity," Genetics in Medicine, vol. 12, no. 10, pp. 641-647, 2010.

[55] D. T. ller, R. Nasir, M. M. Sobeih, Y. Shen, B. L. Wu, and E. Hanson, "16p11.2 microdeletion," in GeneReviews, R. A. Pagon, T. D. Bird, C. R. Dolan, K. Stephens, and M. P. Adam, Eds., University of Washington, Seattle, Wash, USA, 2009.

[56] S. Jacquemont, A. Reymond, F. Zufferey et al., "Mirror extreme BMI phenotypes associated with gene dosage at the chromosome 16p11.2 locus," Nature, vol. 478, pp. 97-102, 2011.

[57] D. Ren, M. Li, C. Duan, and L. Rui, "Identification of SH2$B$ as a key regulator of leptin sensitivity, energy balance, and body weight in mice," Cell Metabolism, vol. 2, no. 2, pp. 95104, 2005.

[58] M. Shinawi, P. Liu, S. H. L. Kang et al., "Recurrent reciprocal 16 p11.2 rearrangements associated with global developmental delay, behavioural problems, dysmorphism, epilepsy, and abnormal head size," Journal of Medical Genetics, vol. 47, no. 5, pp. 332-341, 2010. 
[59] H. Choquet and D. Meyre, "Genomic insights into earlyonset obesity," Genome Medicine, vol. 2, no. 6, article 36, 2010.

[60] M. G. Logan and M. S. Pepper, "The genetics of obesity: the role of the melanocortin 4 receptor," Journal of Endocrinology, Metabolism and Diabetes of South Africa, vol. 15, no. 1, pp. 45-47, 2010.

[61] J. L. Holder Jr., N. F. Butte, and A. R. Zinn, "Profound obesity associated with a balanced translocation that disrupts the SIM1 gene," Human Molecular Genetics, vol. 9, no. 1, pp. 101$108,2000$.

[62] M. C. Bonaglia, R. Ciccone, G. Gimelli et al., "Detailed phenotype-genotype study in five patients with chromosome 6q16 deletion: narrowing the critical region for Prader-Willilike phenotype," European Journal of Human Genetics, vol. 16, no. 12, pp. 1443-1449, 2008.

[63] J. Gray, G. S. H. Yeo, J. J. Cox et al., "Hyperphagia, severe obesity, impaired cognitive function, and hyperactivity associated with functional loss of one copy of the brain-derived neurotrophic factor (BDNF) gene," Diabetes, vol. 55, no. 12, pp. 3366-3371, 2006.

[64] J. C. Han, Q. R. Liu, M. Jones et al., "Brain-derived neurotrophic factor and obesity in the WAGR syndrome," The New England Journal of Medicine, vol. 359, pp. 918-927, 2008.

[65] G. S. H. Yeo, C. C. C. Hung, J. Rochford et al., "A de novo mutation affecting human $\operatorname{TrkB}$ associated with severe obesity and developmental delay," Nature Neuroscience, vol. 7, no. 11, pp. 1187-1189, 2004.

[66] T. Rankinen, A. Zuberi, Y. C. Chagnon et al., "The human obesity gene map: the 2005 update," Obesity, vol. 14, no. 4, pp. 529-644, 2006.

[67] S. B. Cassidy and D. J. Driscoll, "Prader-Willi syndrome," European Journal of Human Genetics, vol. 17, no. 1, pp. 3-13, 2009.

[68] B. M. Herrera, S. Keildson, and C. M. Lindgren, "Genetics and epigenetics of obesity," Maturitas, vol. 69, no. 1, pp. 4149, 2011.

[69] T. Sahoo, D. Del Gaudio, J. R. German et al., "Prader-Willi phenotype caused by paternal deficiency for the HBII-85 C/D box small nucleolar RNA cluster," Nature Genetics, vol. 40, no. 6, pp. 719-721, 2008.

[70] A. J. de Smith, C. Purmann, R. G. Walters et al., "A deletion of the HBII-85 class of small nucleolar RNAs (snoRNAs) is associated with hyperphagia, obesity and hypogonadism," Human Molecular Genetics, vol. 18, no. 17, pp. 3257-3265, 2009.

[71] A. L. Duker, B. C. Ballif, E. V. Bawle et al., "Paternally inherited microdeletion at $15 \mathrm{q} 11.2$ confirms a significant role for the SNORD116 C/D box snoRNA cluster in Prader-Willi syndrome," European Journal of Human Genetics, vol. 18, no. 11, pp. 1196-1201, 2010.

[72] D. Kanber, J. Giltay, D. Wieczorek et al., "A paternal deletion of MKRN3, MAGEL2 and NDN does not result in PraderWilli syndrome," European Journal of Human Genetics, vol. 17, no. 5, pp. 582-590, 2009.

[73] Y. Chen, Y. J. Liu, Y. F. Pei et al., “Copy number variations at the prader-Willi syndrome region on chromosome 15 and associations with obesity in whites," Obesity, vol. 19, no. 6, pp. 1229-1234, 2011.

[74] Y.-C. Hsiao, K. Tuz, and R. J. Ferland, "Trafficking in and to the primary cilium," Cilia, vol. 1, article 4, 2012.

[75] D. F. Guo and K. Rahmouni, "Molecular basis of the obesity associated with Bardet-Biedl syndrome," Trends in
Endocrinology and Metabolism, vol. 22, no. 7, pp. 286-293, 2011.

[76] M. Benzinou, A. Walley, S. Lobbens et al., "Bardet-Biedl syndrome gene variants are associated with both childhood and adult common obesity in French Caucasians," Diabetes, vol. 55, no. 10, pp. 2876-2882, 2006.

[77] P. L. Beales, "Lifting the lid on Pandora's box: the BardetBiedl syndrome," Current Opinion in Genetics and Development, vol. 15, no. 3, pp. 315-323, 2005.

[78] J. D. Marshall, P. Maffei, G. B. Collin, and J. K. Naggert, "Alström syndrome: genetics and clinical overview," Current Genomics, vol. 12, no. 3, pp. 225-235, 2011.

[79] D. Girard and N. Petrovsky, "Alström syndrome: insights into the pathogenesis of metabolic disorders," Nature Reviews Endocrinology, vol. 7, no. 2, pp. 77-88, 2011.

[80] D. Jenkins, D. Seelow, F. S. Jehee et al., "RAB23 mutations in Carpenter syndrome imply an unexpected role for hedgehog signaling in cranial-suture development and obesity," American Journal of Human Genetics, vol. 80, pp. 1162-1170, 2007.

[81] F. Simpson, M. C. Kerr, and C. Wicking, "Trafficking, development and hedgehog," Mechanisms of Development, vol. 126, no. 5-6, pp. 279-288, 2009.

[82] W. Seifert, J. Kühnisch, T. Maritzen, D. Horn, V. Haucke, and H. C. Hennies, "Cohen syndrome-associated protein, $\mathrm{COH} 1$, is a novel, giant Golgi matrix protein required for Golgi integrity," The Journal of Biological Chemistry, vol. 286, pp. 37665-37675, 2011.

[83] B. Budny, M. Badura-Stronka, A. Materna-Kiryluk et al., "Novel missense mutations in the ubiquitination-related gene UBE2A cause a recognizable X-linked mental retardation syndrome," Clinical Genetics, vol. 77, no. 6, pp. 541-551, 2010.

[84] P. S. Tarpey, F. L. Raymond, S. O’Meara et al., "Mutations in CUL4B, which encodes a ubiquitin E3 ligase subunit, cause an X-linked mental retardation syndrome associated with aggressive outbursts, seizures, relative macrocephaly, central obesity, hypogonadism, pes cavus, and tremor," American Journal of Human Genetics, vol. 80, no. 2, pp. 345-352, 2007.

[85] S. R. Williams, M. A. Aldred, V. M. Der Kaloustian et al., "Haploinsufficiency of HDAC4 causes brachydactyly mental retardation syndrome, with brachydactyly type E, developmental delays, and behavioral problems," American Journal of Human Genetics, vol. 87, no. 2, pp. 219-228, 2010.

[86] T. Kleefstra, M. Smidt, M. J. G. Banning et al., "Disruption of the gene Euchromatin Histone Methyl Transferase1 (EuHMTase1) is associated with the $9 \mathrm{q} 34$ subtelomeric deletion syndrome," Journal of Medical Genetics, vol. 42, no. 4, pp. 299-306, 2005.

[87] T. Kleefstra, W. A. Van Zelst-Stams, W. M. Nillesen et al., "Further clinical and molecular delineation of the $9 \mathrm{q}$ subtelomeric deletion syndrome supports a major contribution of EHMT1 haploinsufficiency to the core phenotype," Journal of Medical Genetics, vol. 46, no. 9, pp. 598-606, 2009.

[88] R. E. Slager, T. L. Newton, C. N. Vlangos, B. Finucane, and S. H. Elsea, "Mutations in RAI1 associated with Smith-Magenis syndrome," Nature Genetics, vol. 33, no. 4, pp. 466-468, 2003.

[89] E. A. Edelman, S. Girirajan, B. Finucane et al., "Gender, genotype, and phenotype differences in Smith-Magenis syndrome: a meta-analysis of 105 cases," Clinical Genetics, vol. 71, no. 6, pp. 540-550, 2007.

[90] S. Girirajan, H. T. Truong, C. L. Blanchard, and S. H. Elsea, "A functional network module for Smith-Magenis syndrome," Clinical Genetics, vol. 75, no. 4, pp. 364-374, 2009. 
[91] J. C. Han, M. J. Muehlbauer, H. N. Cui, C. B. Newgard, and A. M. Haqq, "Lower brain-derived neurotrophic factor in patients with Prader-Willi syndrome compared to obese and lean control subjects," Journal of Clinical Endocrinology and Metabolism, vol. 95, no. 7, pp. 3532-3536, 2010.

[92] B. Burns, K. Schmidt, S. R. Williams, S. Kim, S. Girirajan, and S. H. Elsea, "Rail haploinsufficiency causes reduced Bdnf expression resulting in hyperphagia, obesity and altered fat distribution in mice and humans with no evidence of metabolic syndrome," Human Molecular Genetics, vol. 19, no. 20, Article ID ddq317, pp. 4026-4042, 2010.

[93] R. E. Falk and K. A. Casas, "Chromosome 2q37 deletion: clinical and molecular aspects," American Journal of Medical Genetics, Part C, vol. 145, no. 4, pp. 357-371, 2007.

[94] S. K. Shapira, C. McCaskill, H. Northrup et al., "Chromosome 1p36 deletions: the clinical phenotype and molecular characterization of a common newly delineated syndrome," American Journal of Human Genetics, vol. 61, no. 3, pp. 642650, 1997.

[95] A. Battaglia, H. E. Hoyme, B. Dallapiccola et al., "Further delineation of deletion 1 p36 syndrome in 60 patients: a recognizable phenotype and common cause of developmental delay and mental retardation," Pediatrics, vol. 121, pp. 404 410, 2008.

[96] C. S. D’Angelo, I. Kohl, M. C. Varela et al., "Extending the phenotype of monosomy 1 p36 syndrome and mapping of a critical region for obesity and hyperphagia," American Journal of Medical Genetics, Part A, vol. 152, no. 1, pp. 102110, 2010.

[97] J. A. Rosenfeld, J. A. Crolla, S. Tomkins et al., "Refinement of causative genes in monosomy 1p36 through clinical and molecular cytogenetic characterization of small interstitial deletions," American Journal of Medical Genetics, Part A, vol. 152, no. 8, pp. 1951-1959, 2010.

[98] J. A. Rosenfeld, D. Amrom, E. Andermann et al., "Genotypephenotype correlation in interstitial $6 \mathrm{q}$ deletions: a report of 12 new cases," Neurogenetics, vol. 13, no. 1, pp. 31-47, 2012.

[99] D. R. Stewart and T. Kleefstra, "The chromosome 9q subtelomere deletion syndrome," American Journal of Medical Genetics, Part C, vol. 145, no. 4, pp. 383-392, 2007.

[100] V. Cormier-Daire, F. Molinari, M. Rio et al., "Cryptic terminal deletion of chromosome 9q34: a novel cause of syndromic obesity in childhood?" Journal of Medical Genetics, vol. 40, no. 4, pp. 300-303, 2003.

[101] T. Kleefstra, J. M. Kramer, K. Neveling et al., "Disruption of an EHMT1-associated chromatin-modification module causes intellectual disability," The American Journal of Human Genetics, vol. 91, no. 1, pp. 73-82, 2011.

[102] M. H. Willemsen, A. Vallès, L. A. Kirkels et al., "Chromosome 1p21. 3 microdeletions comprising DPYD and MIR137 are associated with intellectual disability," Journal of Medical Genetics, vol. 48, pp. 810-818, 2011.

[103] S. J. C. Stevens, C. M. A. van Ravenswaaij-Arts, J. W. H. Janssen et al., "MYT1L is a candidate gene for intellectual disability in patients with 2p25.3 (2pter) deletions," American Journal of Medical Genetics Part A, vol. 155, pp. 2739-2745, 2011.

[104] C. Wentzel, S. A. Lynch, E. L. Stattin, F. H. Sharkey, G. Annerén, and A. C. Thuresson, "Interstitial deletions at 6q14.1-q15 associated with obesity, developmental delay and a distinct clinical phenotype," Molecular Syndromology, vol. 1, no. 2, pp. 75-81, 2010.

[105] M. Shinawi, T. Sahoo, B. Maranda et al., "11p14.1 microdeletions associated with ADHD, autism, developmental delay, and obesity," American Journal of Medical Genetics, Part A, vol. 155, no. 6, pp. 1272-1280, 2011.

[106] J. Davidsson, K. Jahnke, M. Forsgren, A. Collin, and M. Soller, "Dup(19)(q12q13.2): array-based genotypephenotype correlation of a new possibly obesity-related syndrome," Obesity, vol. 18, no. 3, pp. 580-587, 2010.

[107] M. J. Dasouki, E. L. Youngs, and K. Hovanes, "Structural chromosome abnormalities associated with obesity: report of four new subjects and review of literature," Current Genomics, vol. 12, no. 3, pp. 190-203, 2011.

[108] D. T. Miller, M. P. Adam, S. Aradhya et al., "Consensus statement: chromosomal microarray is a first-tier clinical diagnostic test for individuals with developmental disabilities or congenital anomalies," American Journal of Human Genetics, vol. 86, no. 5, pp. 749-764, 2010.

[109] H. M. Kearney, E. C. Thorland, K. K. Brown, F. QuinteroRivera, and S. T. South, "American College of Medical Genetics standards and guidelines for interpretation and reporting of postnatal constitutional copy number variants," Genetics in Medicine, vol. 13, no. 7, pp. 680-685, 2011.

[110] V. Vauthier, S. Jaillard, H. Journel, C. Dubourg, R. Jockers, and J. Dam, "Homozygous deletion of a $80 \mathrm{~kb}$ region comprising the dnaj6c gene and part of the lepr gene on chromosome $1 \mathrm{p} 31.3$ is associated with early onset obesity, mental retardation and epilepsy," Molecular Genetics and Metabolism, vol. 106, no. 3, pp. 345-350, 2012.

[111] N. Rivera-Brugués, B. Albrecht, D. Wieczorek et al., "Cohen syndrome diagnosis using whole genome arrays," Journal of Medical Genetics, vol. 48, no. 2, pp. 136-140, 2011.

[112] C. Redin, S. Le Gras, O. Mhamdi et al., "Targeted highthroughput sequencing for diagnosis of genetically heterogeneous diseases: efficient mutation detection in Bardet-Biedl and Alström Syndromes," Journal of Medical Genetics, vol. 49, no. 8, pp. 502-512, 2012. 


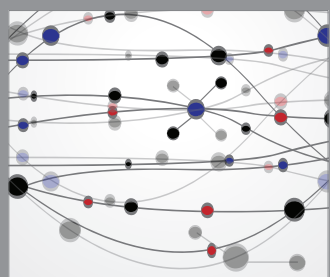

The Scientific World Journal
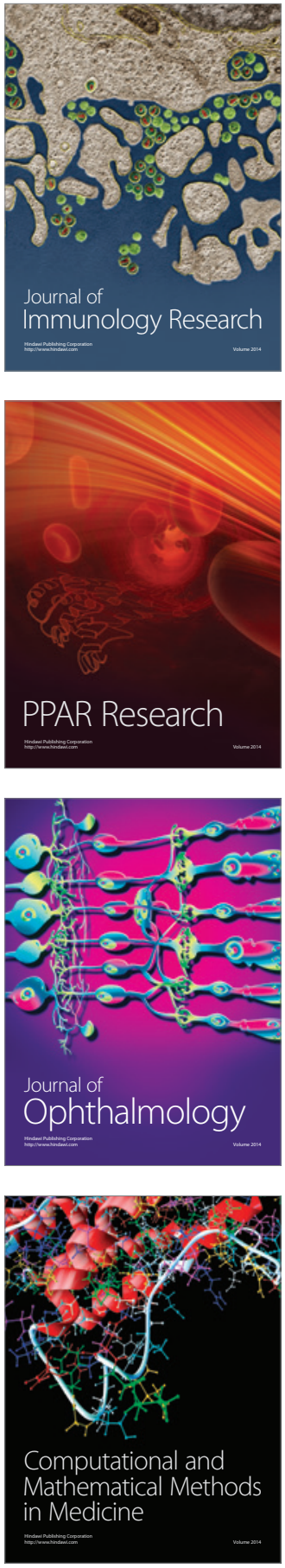

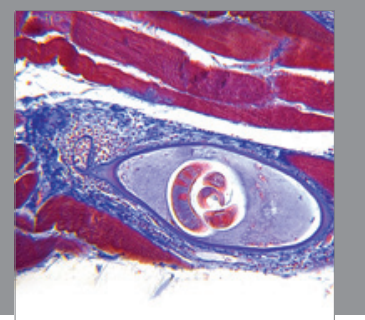

Gastroenterology

Research and Practice
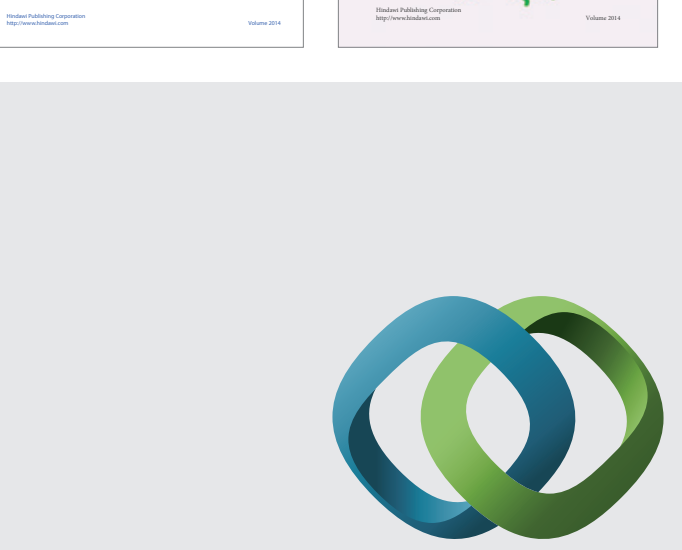

\section{Hindawi}

Submit your manuscripts at

http://www.hindawi.com
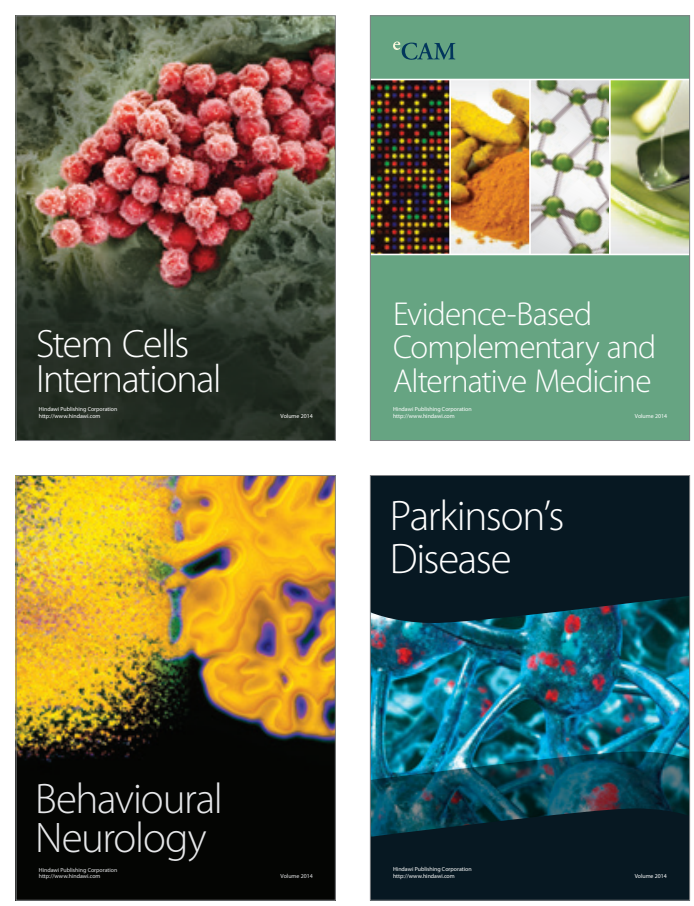

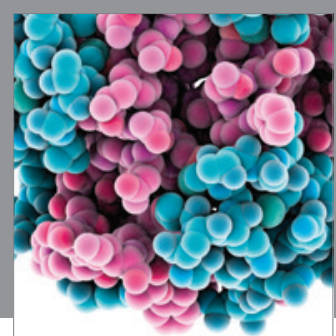

Journal of
Diabetes Research

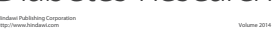

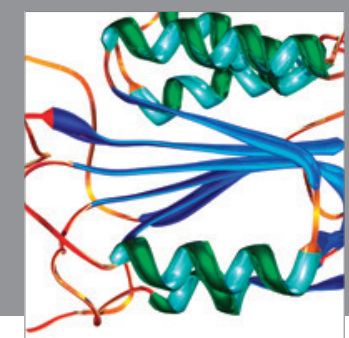

Disease Markers
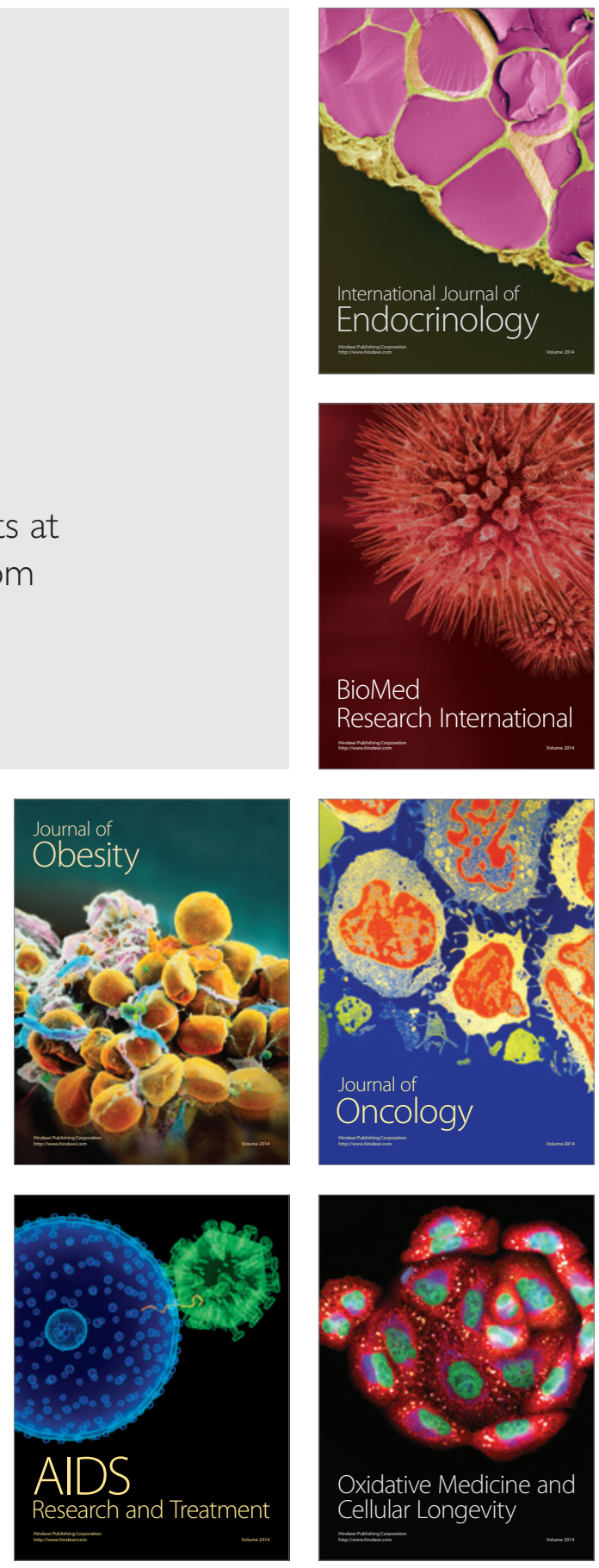